\title{
The health benefits and economic effects of cooperative PM2.5 control: a cost-effectiveness game model
}

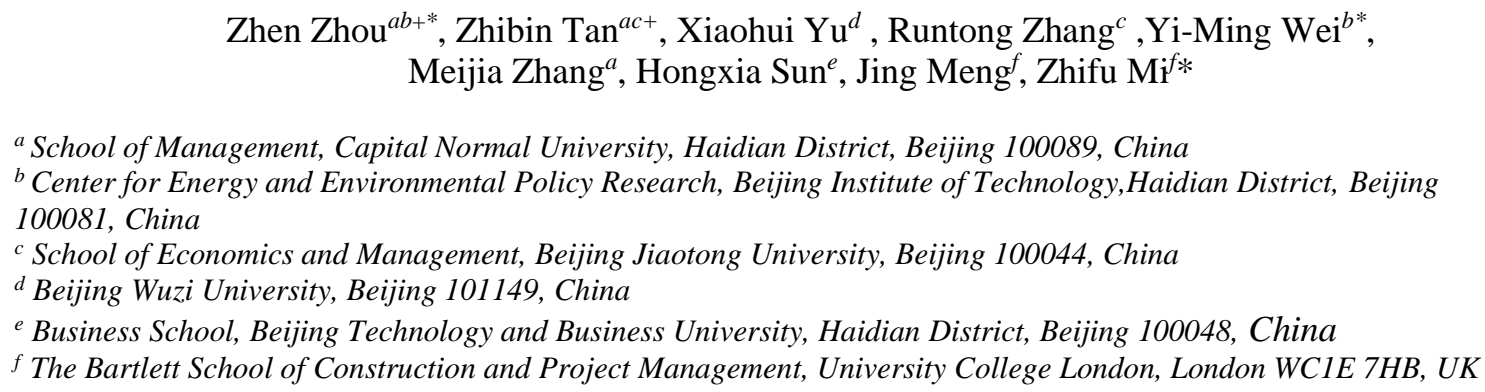

Abstract: In the $\mathrm{PM}_{2.5}$ control of Jing-jin-ji region, the emission reduction target is the decrease of concentration which is different from greenhouse gases control .We constructed a game model of $\mathrm{PM}_{2.5}$ (all particulate matter that has an aerodynamic diameter of 2.5 microns) that is based on the transmission and retention of $\mathrm{PM}_{2.5}$ and that accounts for the direct costs, economic development effects and health benefits of the control of $\mathrm{PM}_{2.5}$. In addition, we conceived a new method to allocate the benefits of cooperative efforts based on changes in welfare. The Beijing-Tianjin-Hebei region of China was studied as an example for this model. The results show that cooperation is an effective strategy for $\mathrm{PM}_{2.5}$ control in this region in 2015. The aggregate indirect cost was $30.87 \%$ lower in the cooperative case than the non-cooperative case. Cooperation increases the health benefits and economic effects by 2.3 billion Yuan. The most negative effects of economic development come from manufacturing and industry, and the health benefits of free rider are small based on transmission matrix. Compared with Hebei which owes the lowest cost, Beijing and Tianjin are more suitable to undertake more $\mathrm{PM}_{2.5}$ control tasks in the cooperation because of their special transmission matrix and regional center location. Our research reveals the importance of transmission matrix in the control of air pollutants, the characteristics of $\mathrm{PM}_{2.5}$ control and give policy implications based on our empirical study and game model.

Keywords: $\mathrm{PM}_{2.5}$ control; Cost-effectiveness game model; Health benefits; Transmission matrix; Pollution control; Jing-jin-ji

\section{Introduction}

$\mathrm{PM}_{2.5}$ is becoming a serious environmental problem in China, especially in the BeijingTianjin-Hebei (Jing-jin-ji) region. According to the data published by the Ministry of Environmental Protection, among the top 10 cities with serious air pollution, 6 cities are in

\footnotetext{
Co-corresponding authors.E-mail address: zhen_cnu@qq.com (Z.Z.),ymwei@263.net (Y.W.), z.mi@ucl.ac.uk (Z.M.),

Co-first authors.
} 
the Jing-jin-ji region. The control of $\mathrm{PM}_{2.5}$ involves issues like the control of other types of air pollution, such as negative externality, publicity, politics and synthesis. The traditional local-regional control method uses resources with low efficiency, is unable to control air pollution effectively, and can even develop a tendency towards increasing contamination. In addition, Zhou et al. (2017) showed that it is difficult to control the $\mathrm{PM}_{2.5}$ in the Jing-jin-ji region without government subsidies due to high direct costs and that cross-region cooperative control is the only way to solve the local regional control problem.

To regulate air pollution cross-region cooperative control, the United States Congress established the Environmental Protection Agency in 1970. The agency divided the United States into 10 large areas and established a series of regional air pollution joint control institutions. Twenty-one countries of the EU signed the Helsinki Treaty in Finland in 1985, began to adopt joint control measures for sulfur dioxide pollution and achieved great success. Zhao et al. (2013), Xue J et al. (2014, 2015), and Wu et al. (2015) measured $\mathrm{SO}_{2}$ removal costs in the Jing-jin-ji region and used game theory to allocate benefits. Shi et al. (2016) used the same model to study the $\mathrm{SO}_{2}$ removal cost in Changsha, Zhuzhou and Xiangtan and indicated that a cooperative strategy would save 208 million Yuan. These studies only consider the direct costs of $\mathrm{SO}_{2}$. In $\mathrm{PM}_{2.5}$ control, there are two important aspects in addition to the direct costs: (1) The health benefits of $\mathrm{PM}_{2.5}$ control. It is widely recognized that $\mathrm{PM}_{2.5}$ threatens human health; thus, $\mathrm{PM}_{2.5}$ control can provide health benefits. According to Aunan and Pan (2004), short-term or long-term exposure to particulate matter can have adverse effects on human health, including short-term acute symptoms, increased mortality from chronic diseases, respiratory system and cardiovascular and cerebrovascular diseases, etc. According to Yu et al. (2015), if the Chinese Air Pollution Prevention Action Plan was implemented as planned, the annual health gains would reach 8.7 billion Yuan. (2) The economic development effects of $\mathrm{PM}_{2.5}$ control. Jorgenson and Wilcoxen (1990), Nondo C et al. (2010), and Baiti et al. (2017) studied the impact of environmental regulation on economic growth. Jorgenson and Wilcoxen (1990) showed that the cost of pollution control has exceeded $10 \%$ of the aggregate cost of government procurement of goods and services in the United States. In summary, in the control of $\mathrm{PM}_{2.5}$ and other air pollutants, the government must take into account the direct costs, economic development effects and health benefits to make multiobjective decisions. In recent research, Xie et al. (2016) constructed a model with the purpose of maximizing the health benefits while reducing the direct costs and studied the methods adopted by Shanghai and other provinces. These existing $\mathrm{SO}_{2}$ cooperation models often employ a large bubble hypothesis as a prerequisite for the aggregate emission control like greenhouse gas control. Greenhouse gas control is a grand proposition, even including coal-electricity price (Fan et al., 2016), production structure (Fan et al., 2019). However, the hypothesis does not make sense because air pollutions such as $\mathrm{SO}_{2}$ are harmful to human health when their concentration are beyond the restricted limitation in each region. In $\mathrm{PM}_{2.5}$ control, the government claims the concentration control of $\mathrm{PM}_{2.5}$. The central government asked the provinces of Beijing, Tianjin, and Hebei to decrease the $\mathrm{PM}_{2.5}$ to 4.2 $\mu \mathrm{g} / \mathrm{m}^{3}, 2 \mu \mathrm{g} / \mathrm{m}^{3}$, and $7.2 \mu \mathrm{g} / \mathrm{m}^{3}$ in 2015 , respectively. For $\mathrm{PM}_{2.5}$ control, the emission reduction target is a decrease in $\mathrm{PM}_{2.5}$ concentration within a certain province. Thus, the large bubble hypothesis is not suitable for $\mathrm{PM}_{2.5}$ control. There are few studies on $\mathrm{PM}_{2.5}$ cooperative control due to the following: (1) $\mathrm{PM}_{2.5}$ has only caught the public's attention 90 in recent years, and pertinent research has failed to be carried out. (2) The composition of 
$91 \mathrm{PM}_{2.5}$ is complex and is different in each region (Yao et al., 2013; Liu et al., 2015; Tang et 92 al., 2017).

93 In the present study, we built a game model that satisfies the minimum direct costs, the maximum health benefits and the minimum effect of economic development. Our study has the following contributions: (1) The concentration-based air pollution control model is originally proposed from cooperative management prospection. (2) The co-benefits of $\mathrm{PM}_{2.5}$ control is considered into the cooperative game model including the direct costs of $\mathrm{PM}_{2.5}$, the effect on economic development and the health benefits of controlling $\mathrm{PM}_{2.5}$ based on the transmission and retention of $\mathrm{PM}_{2.5}$. (3) The welfare function and the contribution of the coalition to aggregate cost-effectiveness are created for the allocation of the cooperative benefits. Compare to the previous literature about $\mathrm{SO}_{2}$ control (Zhao et al. (2013), Xue J et al. (2014, 2015), Wu et al. (2015), and Shi et al. (2016) ( $\mathrm{SO}_{2}$ control is the most important mission before $\mathrm{PM}_{2.5}$ control), The key in our work is that we reveal the unique emission reduction target in $\mathrm{PM}_{2.5}$ control based on the transmission and retention of $\mathrm{PM}_{2.5}$. In the unique emission reduction target, cooperation is a natural select and does not need the any additional hypothesis. Our cost-effectiveness game model provides an explanation why local governments over-achieve goals even if control benefits are less than control costs. Compare to Xie et al. (2016) of $\mathrm{SO}_{2}$ control model based on cost-effectiveness, we consider the effect on economic development of control and improve its allocation way to ensure the superadditivity which it is very important in cooperation game. We also supply the meaning of cost-effectiveness in the air pollution control which is not mentioned.

113 The remainder of this paper is organized as follows. In Section 2, we introduce the $\mathrm{PM}_{2.5}$ control relevant function. In Section 3, we present cost-benefit game model. In Section 4, we compare the situation of cooperation and non-cooperation in the Jing-jin-ji region. Section 5 provides the summary and outlook.

\section{Methodology}

\section{1 $\quad$ PM$_{2.5}$ Concentration and Removal}

In Table 1, we summarize the set, parameters, and variables involved in the model. We assume that a set $N=\{1,2,3 \ldots . . n\}$ is a collection of all the provinces in the model; $i, j \in N$ are two random provinces.

124 


\begin{tabular}{|c|c|c|}
\hline$P_{i}$ & Emissions of $\mathrm{PM}_{2.5}$ in the province $i$ in the current year & $10^{4}$ tons \\
\hline$P_{i P P M_{2.5}}$ & $\begin{array}{l}\text { Emissions of primary } \mathrm{PM}_{2.5} \text { in the province } i \text { in the current } \\
\text { year }\end{array}$ & $10^{4}$ tons \\
\hline$P_{i S O_{2}}$ & Emissions of $\mathrm{SO}_{2}$ in the province $i$ in the current year & $10^{4}$ tons \\
\hline$P_{i N O_{X}}$ & Emissions of $\mathrm{NO}_{\mathrm{X}}$ in the province $i$ in the current year & $10^{4}$ tons \\
\hline$P_{i}^{\prime}$ & Emissions of $\mathrm{PM}_{2}$ in the province $i$ in the previous year & $10^{4}$ tons \\
\hline$P_{i F}$ & The actual emissions of $\mathrm{PM}_{2.5}$ in the province $i$ & $10^{4}$ tons \\
\hline$C_{i}$ & Control's direct costs of $\mathrm{PM}_{2.5}$ in the province $i$ & $10^{4}$ tons \\
\hline$E_{i}$ & Economic development effect of $\mathrm{PM}_{2.5}$ in the province $i$ & $10^{4}$ Yuan \\
\hline$H_{i}$ & Health benefits of $\mathrm{PM}_{2.5}$ in the province $i$ & $10^{4}$ Yuan \\
\hline$\delta_{i j}$ & $\begin{array}{l}\text { Transmission factor, the portion of } \mathrm{PM}_{2.5} \text { transmitted from } \\
\text { province } i \text { to } j ; i=j \text { means the proportion of } \mathrm{PM}_{2.5} \text { that } \\
\text { remains locally. }\end{array}$ & none \\
\hline$\varsigma_{j i}$ & $\begin{array}{l}\text { Retention factor, province } i \text { 's atmospheric } \mathrm{PM}_{2.5} \text { quality } \\
\text { comes from province } j \text { 's transmission ratio; } i=j \\
\text { indicates that the proportion of province } i \text { emissions } \mathrm{PM}_{2.5} \\
\text { quality come from province } i\end{array}$ & none \\
\hline$\Delta c_{i}$ & Concentration of the $\mathrm{PM}_{2.5}$ decline in province $i$ & $\mu \mathrm{g} / \mathrm{m}^{3}$ \\
\hline$q_{i}^{c_{i}}$ & Environmental capacity when concentration of the $\mathrm{PM}_{2.5}$ is $c_{i}$ & $10^{4}$ tons \\
\hline$S_{i}$ & The area of province $i$ & $\mathrm{~km}^{2}$ \\
\hline$A_{i}$ & $\begin{array}{l}\text { the geographical regional total control coefficient of province } \\
i\end{array}$ & $\begin{array}{l}10^{4} \\
\text { tons } \cdot \mathrm{m}^{3} /\left(\mu \mathrm{g} \cdot \mathrm{km}^{2}\right)\end{array}$ \\
\hline$g_{i}$ & Concentration decline goal of $\mathrm{PM}_{2.5}$ in province $i$ & $\mu \mathrm{g} / \mathrm{m}^{3}$ \\
\hline$\beta_{i}$ & $\begin{array}{l}\text { Correlation coefficient of the concentration of } \mathrm{PM}_{2.5} \text { and } \\
\text { emission in province } i . \beta_{i}=A \times S_{i}\end{array}$ & $10^{10} \mathrm{t} \cdot \mathrm{m}^{3}$ \\
\hline$\alpha_{i \mathrm{SO}_{2}}$ & $\begin{array}{l}\text { The relevant conversion coefficient about } \mathrm{SO}_{2+} \text { of } \\
\text { province } i \text {. }\end{array}$ & none \\
\hline$\alpha_{i N O_{X}}$ & $\begin{array}{l}\text { The relevant conversion coefficient of } \mathrm{NO}_{\mathrm{x}} \text { of province } \\
i \text {. }\end{array}$ & none \\
\hline$W_{i}$ & The emission of exhaust gas in the province $i$ & $10^{4}$ tons \\
\hline$P_{i j \operatorname{Min}}$ & Lower limit of air pollution $j$ removal in province $i$ & $10^{4}$ tons \\
\hline$P_{i j \operatorname{Max}}$ & Upper limit of air pollution $j$ removal in province $i$ & $10^{4}$ tons \\
\hline
\end{tabular}

The concentration emission reduction target decline that the central government issued 128 Thus, $\Delta c_{i} \geq g_{i}$.For $\mathrm{PM}_{2.5}$ control, we first need to determine the relationship between $\mathrm{PM}_{2.5}$ concentration $c_{i}$ and environmental capacity $q_{i}^{c_{i}}$. Environmental capacity indicates that if the amount of $\mathrm{PM}_{2.5}$ emitted by region $i$ is $q_{i}^{c_{i}}$, the $\mathrm{PM}_{2.5}$ concentration in 
the region $i$ will remain $c_{i}$ unchanged.

At present, the way to calculate the environmental capacity can be divided into two categories, one is an iterative algorithm based on the climate model. Xue et al. (2014a.) calculate the environmental capacity based on the iterative algorithm of the CMAQ model. The core process is as Figure 1:

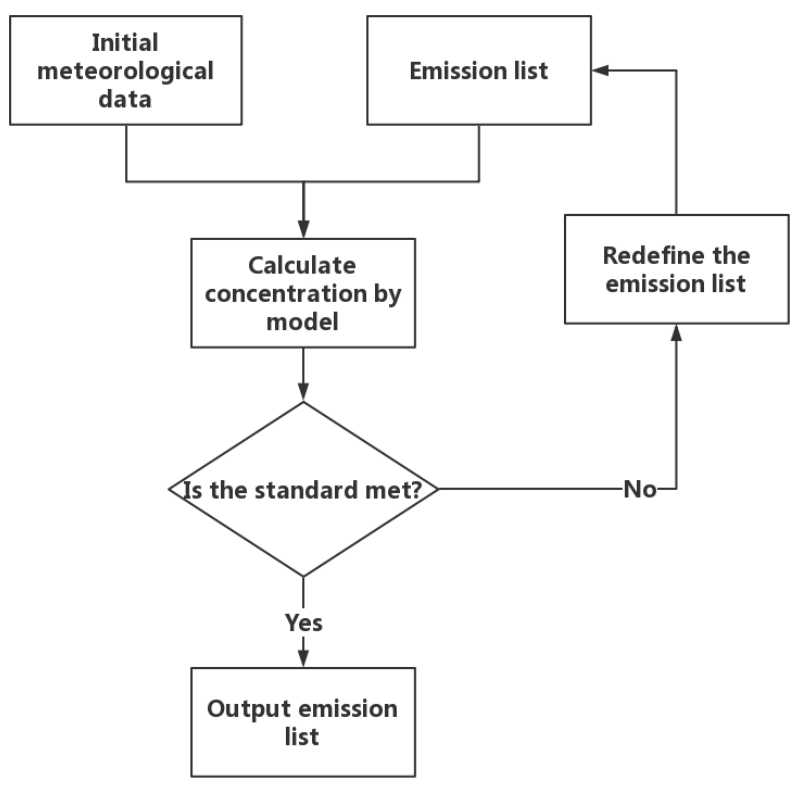

Figure 1: Schematic diagram of iterative algorithm

Based on the original emissions list, we design emission reduction plans to further reduce $\mathrm{PM}_{2.5}$ emissions until the emission reduction targets are completed. Environmental capacity by iterative algorithm obtains is closer to the true value, but the solution process is approximately a black box. The relationship between the simple environmental capacity and the concentration cannot be obtained. For example, by the climate model, we find we need reduce 100,000 tons of $\mathrm{PM}_{2.5}$ emissions if we want to reduce the $\mathrm{PM}_{2.5}$ concentration from $70 \mathrm{ug} / \mathrm{m}^{3}$ to $60 \mathrm{ug} / \mathrm{m}^{3}$. But if we reduce 120,000 tons of $\mathrm{PM}_{2.5}$, how much concentration will drop? We can not draw conclusions from the previously known $10 \mathrm{ug} / \mathrm{m}^{3}$ corresponding to 100,000 tons, and still need re-submit to the climate model for calculation. We can not get explicit expressions from the climate model.

A-value method (Da-hai et al., 2016) is another common way to estimate environmental capacity. The formula A-value method is as follows:

$$
q_{i}^{c_{i}}=A_{i} \times c_{i} \times S_{i}
$$

This method is widely used in the accounting of urban environmental capacity in China due to its ease of use and practicability. Where $c_{i}$ indicates the $\mathrm{PM}_{2.5}$ concentration of the region $i, A_{i}$ is the geographical regional total control coefficient of province $i, S_{i}$ is the area of region $i$. (Da-hai et al., 2016) believes that the A value method is actually a static atmospheric environmental capacity and is also a dynamic atmospheric self-cleaning ability index. This method is relatively simple and has a clear relationship. In a known Avalue and $S_{i}$, for any $c_{i}$, we can directly get its corresponding $q_{i}^{c_{i}}$, due to the use of a 
simple linear relationship to deal with $\mathrm{PM}_{2.5}$ concentration and environmental capacity. Compared with the iterative algorithm, A-value method has a larger error.

In this article, we combine the advantages and disadvantages of these two methods and use the following ways:

(1) The relationship between environmental capacity and concentration used in our paper is as shown in Eq. (1).

(2) In our paper, the difference between the environmental capacity at initial concentration $\rho_{0}$ and the environmental capacity at the goal concentration $\rho_{0}-g_{i}$ specified is solved by iterative algorithm based on the climate model AERMOD. That is, in Eq. (1), $A \times S_{i}$ is solved using the AERMOD model.

This method is equivalent to using the AERMOD model to obtain an accurate environmental capacity $q_{i}^{c_{i}}$ at a concentration of $c_{i}$, and using the A value method to approximate the relationship between $q_{i}^{c_{i}}$ and $c_{i}$ in $c_{i}$ neighborhood. If the players just complete the goals in the final solution, then the environmental capacity at this time is equal to the value solved by the AERMOD model. Compared with the AERMOD iterative algorithm, despite the sacrifice of certain accuracy, this method guarantees the solvability of the plan. Compared with the A-value method, the AERMOD iterative algorithm provides a reference point and improves the accuracy.

The errors in this method are as follows:

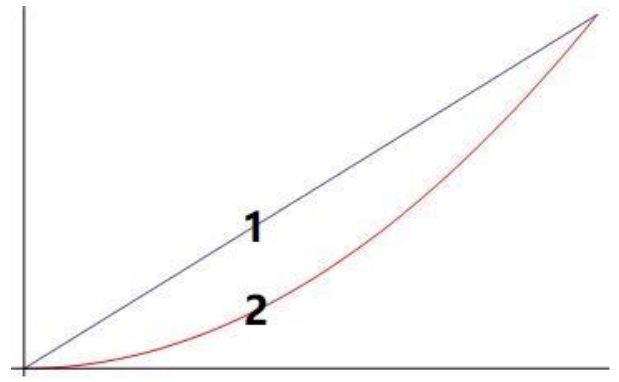

Figure 2: Error description

In Figure 2, line 1 represents the linear relationship between the environmental capacity and the $\mathrm{PM}_{2.5}$ concentration in $\mathrm{A}$ value. Line 2 represents the unknown nonlinear relationship between the environmental capacity and the $\mathrm{PM}_{2.5}$ concentration in the AERMOD. Line 1 and line 2 have the same two endpoint values, and we are equivalent to fitting a nonlinear relationship with a linear relationship. And if the solution of the final model is near the endpoint, the error will be small. Here, we let $\beta_{i}=A \times S_{i}, \beta_{i}$ is also correlation coefficient of the concentration of $\mathrm{PM}_{2.5}$ and emission in province $i$. So $\Delta c_{i}$ can also be expressed as follows:

where $P_{j}$ is the emissions of $\mathrm{PM}_{2.5}$ in province $j$ in the current year. $P_{j}^{\prime}$ is the emission in the previous year. If $\left(P_{j}^{\prime}-P_{j}\right)>0$, Then it will have a positive externality for the treatment of air pollutants, and vice versa. Due to the fluidity of air pollutants, this 
191 externality can have an impact on other provinces in the region. $\delta_{j i}{ }^{1}$ is the ratio of the 192 emission in province $j$ sent to province $i$. Then the difference emission of the $\mathrm{PM}_{2.5}$ from 193 the province $j$ between current year and the previous year the is $\delta_{j i}\left(P_{j}^{\prime}-P_{j}\right)$. The effect of $194 \mathrm{PM}_{2.5}$ concentration in province $i$ is $\delta_{j i}\left(P_{j}^{\prime}-P_{j}\right) / \beta_{i}$. Then the local $\mathrm{PM}_{2.5}$ concentration 195 decline of the province $i$ is the sum of the effects of all provinces. That is $196 \quad P_{i F}=\sum_{j=1}^{n} \delta_{j i}\left(P_{j}^{\prime}-P_{j}\right)$.

197 According to Eq. (2), province $j$ controls the $\mathrm{PM}_{2.5}$ and makes $\left(P_{j}^{\prime}-P_{j}\right)>0$, which not 198 only reduces the $\mathrm{PM}_{2.5}$ concentration in province $j$ but can also reduce the $\mathrm{PM}_{2.5}$ 199 concentration of province $\delta_{i j} \neq 0$.

200 The source of $\mathrm{PM}_{2.5}$ is complex, including primary $\mathrm{PM}_{2.5}$, and also secondary $\mathrm{PM}_{2.5}$ 201 generated by physicochemical reaction of other air pollutants such as $\mathrm{NO}_{\mathrm{X}}$ and $\mathrm{SO}_{2}$ in the air. According to the requirements of the "Technical Guidelines for Environmental Impacts Assessment - Atmospheric Environment" of the Ministry of Ecology and Environment of the People's Republic of China, for the AERMOD model, we evaluate the effect of $\mathrm{NO}_{\mathrm{X}}$, $\mathrm{SO}_{2}$ on secondary $\mathrm{PM}_{2.5}$ generated in air, and just use the coefficient method to convert emissions of $\mathrm{NO}_{x}, \mathrm{SO}_{2}$ to $\mathrm{PM}_{2.5}$ concentration,

$$
P_{i}=P_{i P P M_{2.5}}+\alpha_{i S O_{2}} P_{i S O_{2}}+\alpha_{i N O_{X}} P_{i N O_{X}}
$$

$P_{i}$ is $\mathrm{PM}_{2.5}$ emission of the player $i$, it is the sum of the three parts, including primary $\mathrm{PM}_{2.5}$ and secondary $\mathrm{PM}_{2.5}$ generated by $\mathrm{SO}_{2}$ and $\mathrm{NO}_{\mathrm{X}} . \alpha_{i S O_{2}}, \alpha_{i N O_{X}}$ is the relevant conversion coefficient. Here, we choose the recommended settings $\alpha_{\mathrm{iSO}_{2}}=0.58$, $\alpha_{i N O_{X}}=0.44$ of the Ministry of Ecology and Environment ( CHINA, M. O. E. E., 2018).

\subsection{Direct Cost Function}

In terms of the direct cost of air pollutants, Zhao et al. (2013), Xue et al. (2014, 2015) and $\mathrm{Wu}$ et al. (2015) constructed the pollutant removal function based on the models of $\mathrm{Du}$ et al. (2007) and Cao et al. (2009).

The pollutant direct cost function form constructed by Cao et al. (2009), the cost model of air pollutants control is established:

$$
C_{i}\left(P_{i j}\right)=\theta \cdot W_{i}^{\varphi} \cdot \prod\left(P_{i j}^{i n d u s t r y}\right)^{\mu_{j}}
$$

Among them, $C_{i}$ is the cost of air pollutants in province $i, W_{i}$ is the emission of exhaust gas in the province $i$, and $P_{i j}^{i n d u s t r y}$ is the industrial emissions of the $j$ th air pollutant in the region $i, \theta, \varphi, \mu_{j}$ are parameters.

In our paper, $\mathrm{PM}_{2.5}$ emissions include both industrial and non-industrial parts. We do not discuss the non-industrial emission of $\mathrm{PM}_{2.5}$. The lower limit of $\mathrm{PM}_{2.5}$ emissions is the

\footnotetext{
${ }^{1}$ The transmission and retention effects of $\mathrm{PM}_{2.5}$ in each of our regions are constant and will be further explained in the appendix 7.1.
} 
emissions of $\mathrm{PM}_{2.5}$ non-industrial part. The emissions of $\mathrm{PM}_{2.5}$ industrial part is $P_{i}-P_{i \text { min }}$. Eq. (4) can be transformed into:

$$
C_{i}\left(P_{i j}\right)=\theta \cdot W_{i}^{\varphi} \cdot \prod\left(P_{i j}-P_{i j \min }\right)^{\mu_{j}}
$$

The industrial air pollutant data collected in the statistical yearbook only includes $\mathrm{SO}_{2}$, $\mathrm{NO}_{x}$, and dust; and the air pollutants in our relevant source data only include $\mathrm{SO}_{2}, \mathrm{NO}_{\mathrm{x}}$, and primary $\mathrm{PM}_{2.5}$. So here we need to convert the dust emissions into primary $\mathrm{PM}_{2.5}$ emission. We use a simple scaling relationship to estimate the conversion relationship between dust and primary $\mathrm{PM}_{2.5}$ in each province. Let $t_{i}=\left(\frac{P_{i P P M_{2.5}}}{P_{i D u s t}}\right)^{\mu_{j}}$, Eq. (5) can be transformed into:

$$
C_{i}\left(P_{i j}\right)=t_{i} \cdot \theta \cdot W_{i}^{\varphi} \cdot \prod\left(P_{i j}-P_{i j \min }\right)^{\mu_{j}}
$$

\subsection{Health Benefit Function}

We selected respiratory disease, cardiovascular disease, chronic and acute bronchitis, and outpatient death as terminals with which to establish the function between the $\mathrm{PM}_{2.5}$ control and health benefits. The following assessment model, based on Delucchi et al. (2002), can be established:

$$
L=\sum_{i=1}^{M} L_{i}=\sum_{i=1}^{M} E_{i} \cdot L_{p i}
$$

where $L$ is the sum of the costs of all health terminals due to the $\mathrm{PM}_{2.5}$ concentration decline, $L_{i}$ is the health costs for health terminal $i, E_{i}$ is the risk of health terminal $i$, and $L_{p i}$ is the value of the unit health risk change to the health terminal $i$.

The risk changes in health terminal $i$ must be determined using environmental health risk assessment methods. Scholars usually use the exposure-response coefficient between the pollutant concentration and health effects to calculate the health effects of $\mathrm{PM}_{2.5}$ changes due to concentration changes, as shown in Eq. (8):

$$
\Delta E=p \cdot I \cdot\left(1-\frac{1}{\exp \left(\beta\left(\rho-\rho_{0}\right)\right)}\right)
$$

where $I$ is the health risk in the actual concentration of $\mathrm{PM}_{2.5}, \quad \beta$ is the exposurereaction coefficient, $\rho$ is the actual concentration of $\mathrm{PM}_{2.5}$, and $\rho_{0}$ is the reference concentration. According to Eq. (1), the concentration of $\mathrm{PM}_{2.5}$ can be transformed with the quality. Thus, Eq.(7)-(8) establish the relationship between the removal of $\mathrm{PM}_{2.5}$ and the health cost.

We use the disease cost method (Huang and Zhang, 2013) to assess the loss caused by respiratory disease, cardiovascular disease, acute bronchitis and outpatient and use the disability adjusted life method (Huang and Zhang, 2013, Miao et al., 2017) to assess the loss caused by chronic bronchitis and the adjusted human resource method (Huang et al., 2012) to assess the loss caused by chronic and acute death.

\section{(1) Health cost assessment of acute disease}


The cost of disease method is used to measure the cost of disease, including medical expenses and work income losses. The calculation is shown in Eq. (9):

$$
c_{i}=\left(c_{P i}+G D P_{P} \cdot T_{L i}\right) \cdot \Delta I_{i}
$$

where $c_{i}$ is the aggregate cost, $c_{P i}$ is the cost of disease for unit cases, $G D P_{P}$ is the average daily per capita GDP, $T_{L i}$ is the work delay time due to illness, and $\Delta I_{i}$ is the change of the health effect.

\section{(2) Health cost assessment of chronic disease}

The disability adjusted life year (Dalys) refers to the loss of all health years from onset to death, including the loss of life caused by premature death and disability. A greater value of a disease indicates a greater health loss. The specific formula is shown in Eq. (10):

$$
\text { Dalys }=\int_{x=\alpha}^{x=\alpha+\beta} c x e^{-\tau x} e^{-\gamma(x-\alpha)} d x
$$

where $\alpha$ is the age of onset, $\beta$ is the loss of life due to premature death, $\gamma$ is the discount rate (the rate in the paper is $7 \%$, which is the current medium and long-term loan interest rate), and $c$ and $\tau$ are constants.

\section{(3) Cost assessment of life expectancy loss}

The adjusted human resource method estimates the cost of premature death from the $\mathrm{PM}_{2.5}$. The specific formula is

$$
H C L=\sum_{k=1}^{t} G D P_{k}^{p v}=G D P_{0} \times \sum_{k=1}^{t}[(1+\alpha) \div(1+r)]^{k}
$$

where $H C L$ represents individual human capital or life value based on per capita GDP, $t$ is the loss of life per year, $G D P_{k}$ is the per capita GDP in the $\mathrm{k}^{\text {th }}$ year, the $G D P_{0}$ is the base year per capita GDP, $\alpha$ is the per capita GDP growth rate, and $r$ is the social discount rate.

$$
\begin{aligned}
H_{i}\left(P_{i F}\right)= & \sum_{j=1}^{6} p_{i} * c_{i j} * I_{j 0}\left(\left(1-\exp \left(\beta_{j}\left(\rho_{i}-\frac{P_{i F}}{\phi_{i}}\right)\right)-\left(1-\exp \left(\beta_{j}\left(\rho_{i}-\rho_{0}\right)\right)\right)\right)\right) \\
& +\sum_{j=7}^{8} p_{i} * H C L_{i j} * I_{j 0}\left(\left(1-\exp \left(\beta_{j}\left(\rho_{i}-\frac{P_{i F}}{\phi_{i}}\right)\right)-\left(1-\exp \left(\beta_{j}\left(\rho_{i}-\rho_{0}\right)\right)\right)\right)\right) \\
& +p_{i} * c_{i 9} * I_{90} * \text { Dalys } *\left(\left(1-\exp \left(\beta_{j}\left(\rho_{i}-\frac{P_{i F}}{\phi_{i}}\right)\right)-\left(1-\exp \left(\beta_{j}\left(\rho_{i}-\rho_{0}\right)\right)\right)\right)\right)
\end{aligned}
$$

\subsection{Economic Development Effects Function}

$\mathrm{PM}_{2.5}$ control measures must adjust the industrial structure and shut down certain polluting enterprises while it also promotes the development of transportation and tourism (Li, 2014). There are 41 industries in Table 5 of Appendix 7.2.3. The aggregate economic effects in province $i$ in 2015 due to environmental controls can be expressed as follows:

$$
E_{i}^{2015}=\sum_{\mathrm{n}=1}^{41} \omega_{n i} \cdot p_{n i}
$$

where $\omega_{n i}$ is the coefficient related to the influence of environmental regulations for industry $n$ in 2015 and $p_{n i}$ is the GDP of industry $n$. 


$$
E_{i}\left(P_{i}\right)=\tau \cdot \frac{E_{i}^{2015} P_{i}^{2015}}{\left(P_{i}-P_{i \min }\right)}
$$

where $P_{i}^{2015}$ is the real emission in emission, $P_{i}$ is the emission that we want to solve

299

300

301

302

303

304

305

306

307

308

309

312

313

314

315

316

317

318

319

320

321

322

323

324

325

326

327

328

329

330 and $\tau$ is the conversion factor between different years. If the year is $2015, \tau$ is 1 . In Eq. (14), a positive value means that the $\mathrm{PM}_{2.5}$ has a negative effect on economic development; a negative value means that the $\mathrm{PM}_{2.5}$ has a positive effect on economic development.

\subsection{The Cost-benefit Game Model}

Suppose that a set $N=\{1,2,3 \ldots \ldots n\}$ is a collection of all of the provinces in the model, $S=\{1,2,3 \ldots \ldots|S|\}$ is a coalition, and $S \subseteq N$. Then, coalition $S$ 's $\mathrm{PM}_{2.5}$ control game model is as is follows:

$$
\text { model is as is follows: }
$$

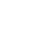

.




$$
\Delta c_{i} \geq g_{i} \quad i \in S
$$

$$
0 \leq P_{i j} \leq P_{i \operatorname{Max}} \quad i \in S
$$

Eq. (19) has been clarified in Eq. (2). For any members of the coalition $i, j \in S$ because $i$ and $j$ are in the same coalition; thus, $i$ can achieve its exact industrial removal target. For the provinces outside the coalition $j \in N / S, i$ cannot achieve the exact $P_{j}$. Thus, it is assumed that its removal in the current year is equal to that of the previous year $P_{j}=P_{j}^{\prime}$ based on the province's past control history. Eq. (20) indicates that each coalition has budgetary limits on direct costs. We assume that each player only pays the minimum direct costs to accomplish the emission reduction target. Therefore, the direct costs budget of coalition $S$ cannot exceed the sum of each member's budget. It also means that in the noncooperation, each province only pursues the least cost of control, and it is just a singleobjective model. Eq. (21) indicates that the decline concentration in each region must at least meet the target $g_{i}$. Eq. (22) indicates that there are an upper limit and lower limit in each province for every kind of air pollutant. In our model, we only discuss the $\mathrm{PM}_{2.5}$ control from industrial part, so the $\mathrm{PM}_{2.5}$ emission's lower limit is other non-industrial part. And according to our observations. After the announcement of the Air Pollution Prevention and Control Plan, the emissions of various pollutants in the Jing-jin-ji region are decreasing year by year, so the $\mathrm{PM}_{2.5}$ emission's upper limit is the previous year's emissions.

\subsection{The Benefits Allocation Model}

According to the previous discussion, cooperation can bring benefits in the control of air pollution. It is important to allocate the benefits of cooperation. Unlike other studies in which the Shapley value was used to allocate the changes of the aggregate costs, the Shapley value (Shapley, 1952) is used here to allocate the changes in welfare.

\subsubsection{Aggregate cost-effectiveness of PM2.5 control}

The central government is concerned about all of the provinces' cost-effectiveness between the the indirect cost (health benefit minus economic development effects) and the direct cost. Thus, we define the aggregate welfare of the optimal removal model as Eq. (23):

$$
G=\frac{\sum_{i=1}^{n}\left(H_{i}-E_{i}\right)}{\sum_{i=1}^{n} C_{i}}
$$

The health benefits are different from that of Eq. (18), which assumes that the qualities of the removal outside of the coalition are equal to those of the previous year and are calculated based on the real industrial removal of all players. Eq. (23) is the costeffectiveness between the indirect cost and the direct cost.

\subsubsection{The contribution of the coalition to aggregate cost-effectiveness}

For any coalition structure $\left\{S^{1}, S^{2}, \cdots S^{m}\right\}$, the aggregate welfare $G$ can also be expressed as 


$$
G=\frac{\sum_{k=1}^{m} \sum_{j=1}^{\left|S^{k}\right|}\left(H_{j}-E_{j}\right)}{\sum_{i=1}^{n} C_{i}} j \in S^{k}, S^{k} \subseteq N
$$

Eq. 31 is the sum of all of the coalition's contributions for the aggregate costeffectiveness. The variable $\tilde{v}(S)$ is the welfare of coalition $S$ :

$$
\tilde{v}(S)=\frac{\sum_{j=1}^{|S|}\left(H_{j}-E_{j}\right)}{\sum_{i=1}^{n} C_{i}}, j \in S
$$

The variable $\tilde{v}(S)$ is different from the Z-value. Whatever the coalition of $\tilde{v}(S)$, its denominator is the same as the direct costs of all of the provinces.

\subsubsection{Benefits allocation according to the Shapley value}

We use the Shapley value to allocate the $\tilde{v}(S)$ changes in the welfare of coalition $S$ after cooperation. Suppose that $\phi=\left\{\phi_{1}, \phi_{2} \ldots \ldots \phi_{n}\right\}$ is a set of assignments to $G$. Then, $\phi_{i}(v)$ is the share of $\mathrm{G}$ in this set of allocation strategies for $i$, as shown in Eq. (26):

$$
\phi_{i}(v)=\sum_{i \in S} W|S| \cdot[\tilde{v}(S \cup\{i\})-\tilde{v}(S)]
$$

$$
\text { where } W|S| \text { is the weight vector, } W|S|=\frac{(n-|S|) !(|S|-1) !}{n !} \text {, and } \tilde{v}(S \cup\{i\}), \tilde{v}(S)
$$
is the welfare of coalition $S$ before and after $i$ joining in the coalition. For $i$, the benefits after allocation are $\phi_{i}(v) \cdot \sum_{i=1}^{n} C_{i}$. Suppose the welfare of $i$ before allocation is $\phi_{i^{\prime}}(v)$. Then, $i$ should transfer the payments $\left[\phi_{i}(v)-\phi_{i^{\prime}}(v)\right] \cdot \sum_{i=1}^{n} C_{i}$.

We choose to allocate $\tilde{v}(S)$ for the following reasons: (1) The optimal solution takes into account 3 emission reduction targets. Thus, the optimal solution does not mean that the aggregate cost $\left(\sum_{i=1}^{n}\left(C_{i}+E_{i}-H_{i}\right)\right)$ is minimal. (2) Although the Z-value is also considered to combine 3 emission reduction targets, the $\mathrm{Z}$ value is not superadditive. The $\tilde{v}(S)$ is additive. From this point of view, every coalition is stable. (3) From the final transfer payments in this section, the allocation of the welfare is also an allocation for the aggregate cost. This program also takes into account the direct costs, economic development effects and health benefits. Therefore, the program is acceptable.

\section{Empirical study}

In our empirical research, the Jing-jin-ji region was studied as an example. A brief introduction of this region is provided in Section 4.1. The model is built and the results are analyzed in Section 4.2. 


\subsection{Study Areas}

402

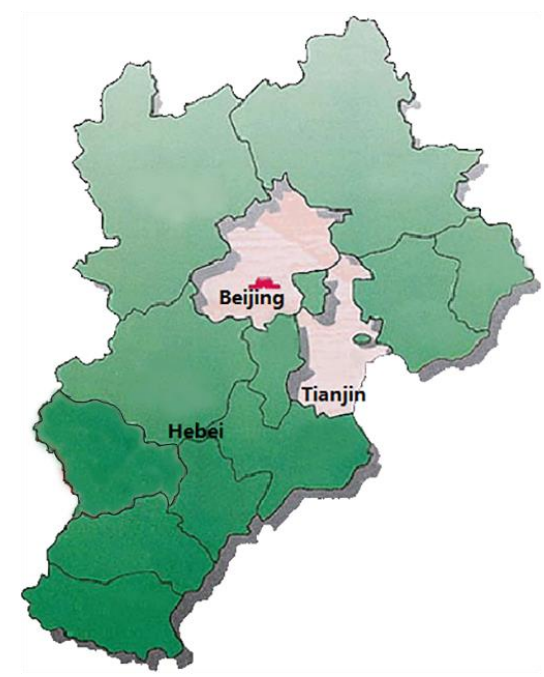

Figure 3 Jing-Jin-Ji Areas

Figure 3 shows the Jing-jin-ji region examined in this study. Beijing and Tianjin are located on the North China Plain. The open terrain is conducive to the spread of $\mathrm{PM}_{2.5}$. The sparse rainfall does not facilitate the precipitation of $\mathrm{PM}_{2.5}$, and it is extremely difficult for this pollutant to be precipitated out (Zhao et al., 2013). Beijing (Jing) has, relative to the other municipalities, the most advanced tertiary industries and higher per capita GDP, followed by Tianjin (Jin), while Hebei (Ji) has a higher proportion of secondary industries and lower per capita GDP. The $\mathrm{PM}_{2.5}$ levels produced by Beijing and Tianjin are much lower than that in Hebei. Thus, the $\mathrm{PM}_{2.5}$ of Beijing and Tianjin mainly arises from Hebei and the people in this province suffer from the $\mathrm{PM}_{2.5}$ transferred into Beijing and Tianjin. For the region, the current situation of $\mathrm{PM}_{2.5}$ control can be very severe, especially in Beijing. In the next section, we will study the situation in 2015. According to relevant government reports, the decline in emission reduction targets of the concentrations for Beijing, Tianjin and Hebei in 2015 were $4.2 \mu \mathrm{g} / \mathrm{m}^{3}, 2 \mu \mathrm{g} / \mathrm{m}^{3}$, and $7.2 \mu \mathrm{g} / \mathrm{m}^{3}$, respectively.

\subsection{Results and Analysis}

The model is operated according to the parameter values in Appendix 7.2 from the China Statistical Yearbook, China Environmental Statistics Yearbook, relevant statistical yearbooks in Beijing, Tianjin, Hebei, and relevant data from MEIC (Liu et al., 2015) (the full cooperation situation is shown, other situations are not shown due to lack of space.), the parameters in the correlation function is shown in Table 2 in Appendix 7.1.

The model is resolved by Mathematica 9.0. In the full cooperation situation, the optimal emissions of Beijing are 4.76 (10 4 tons) primary $\mathrm{PM}_{2.5}, 4.48$ (10 $0^{4}$ tons) $\mathrm{SO}_{2}, 16.94\left(10^{4}\right.$ tons) $\mathrm{NO}_{\mathrm{X}}$ respectively. The total amount emission is equivalent to the discharge of 14.81(10 $10^{4}$ tons) of $\mathrm{PM}_{2.5}$. The optimal emissions of Tianjin are 9.33 (10 $10^{4}$ tons) primary $\mathrm{PM}_{2.5}, 11.40$ (10 4 tons) $\mathrm{SO}_{2}, 40.57$ (10 4 tons) $\mathrm{NO}_{\mathrm{X}}$ respectively. The total amount is equivalent to the discharge of $33.79\left(10^{4}\right.$ tons $)$ of $\mathrm{PM}_{2.5}$. The optimal emissions of Hebei are 77.02 (10 tons) primary $\mathrm{PM}_{2.5}, 113.55$ (10 tons) $\mathrm{SO}_{2}, 183.40$ (10 tons) $\mathrm{NO}_{\mathrm{X}}$ respectively. The total amount is equivalent to the discharge of 223.57 (10 4 tons) of $\mathrm{PM}_{2.5}$. The aggregate welfare is -3.56 . In this situation,the indirect cost caused is 3.56 


\subsubsection{Comparative analysis of cooperation and non-cooperation results}

In the non-cooperation situation, the $\mathrm{PM}_{2.5}$ emission is 19.92 ( $10^{4}$ tons $)$ in Beijing, 38.63 ( $10^{4}$ tons) in Tianjin, and $218.22\left(10^{4}\right.$ tons) in Hebei, and the aggregate removal is 276.77 ( $10^{4}$ tons). Compared with the non-cooperation situation, in the cooperation situation, the emission in Hebei decreased while the emission of Beijing, Tianjin increased, and the aggregate amount of removal also increased. The cost-effectiveness of the region increased by approximately 1.59 Yuan. The benefits increased by 2.318 billion Yuan.

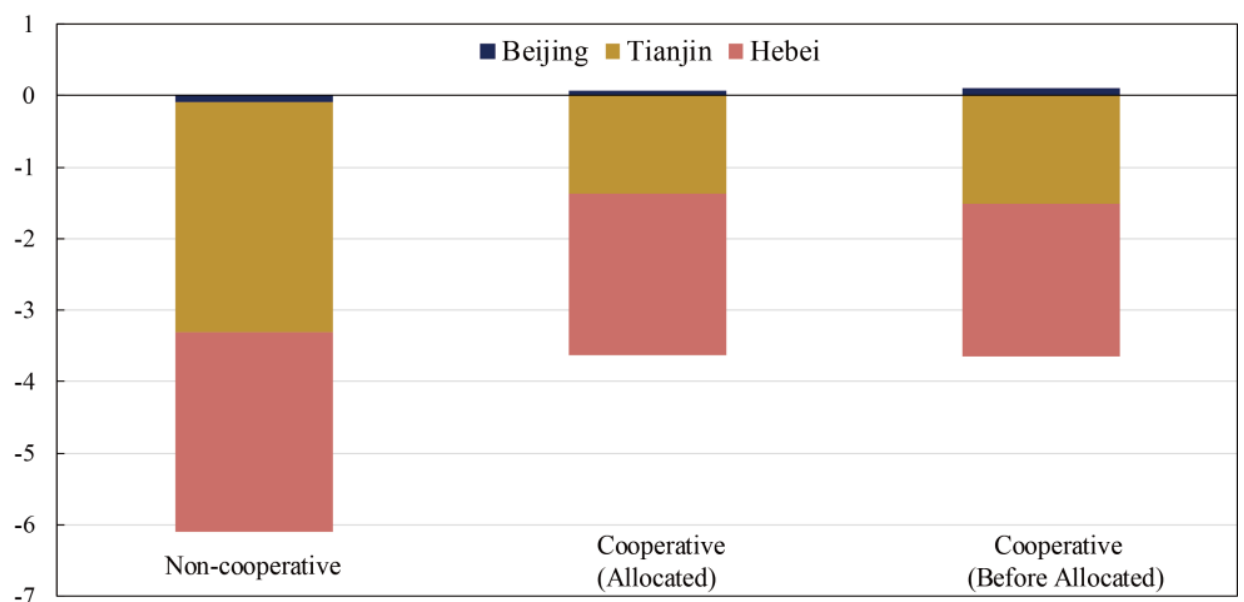

Figure 4 Comparison of cost-effectiveness in cooperation and non-cooperation

Tables 7 in Appendix 7.3 show that Beijing should transfer 0.373 billion Yuan, Tianjin should get 1.995 billion Yuan, and Hebei should transfer 1.622 billion Yuan in the cooperation situation. From Figure 4, after the benefits allocation, the contribution for the aggregate cost-effectiveness is better than the non-cooperation situation. The individual cost-effectiveness of each province is also better than the non-cooperation situations. Therefore, all three provinces have an incentive to engage in cooperation.

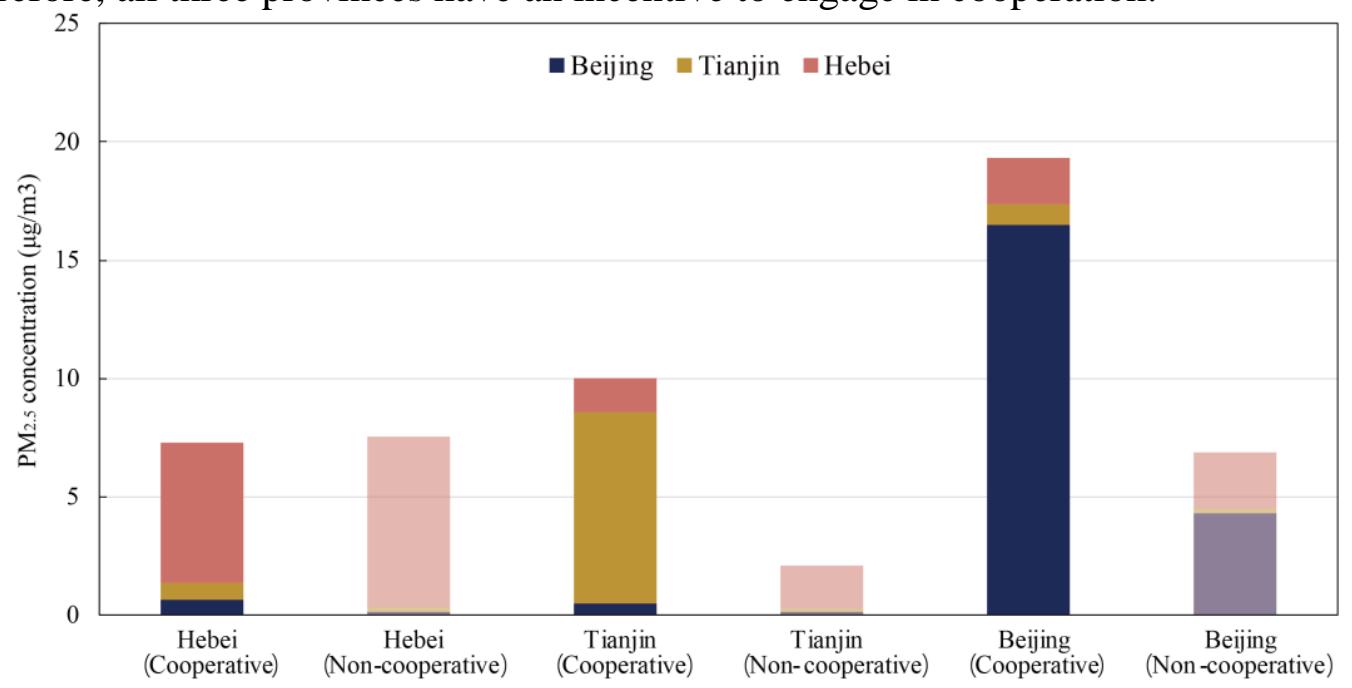

Figure 5 Comparison of $\mathrm{PM}_{2.5}$ concentration decline source in cooperation (dark color) and non-cooperation (light color).

Figure 5 shows that there is a certain difference concerning the $\mathrm{PM}_{2.5}$ concentration 
decline source between the cooperation and non-cooperation situations. The decrease in the concentration in Beijing and Tianjin in the cooperation situation is significantly higher, which is positively correlated with the removals. Compared to the non-cooperation situation, Tianjin and Hebei takes on more responsibilities to reduce the $\mathrm{PM}_{2.5}$ concentration of the region by discharging less $\mathrm{PM}_{2.5}$ locally.

It is worth noting that Beijing and Tianjin governments will receive the most of benefits in their own local emissions reduction because the very limited transmission factors from Hebei and their center location of the Jing-jin-ji region as shown in Figure 3. Once Beijing or Tianjin removes the emissions the two other provinces of the Jing-jin-ji region, especially Hebei for it's around location, will receive the most positive external benefits. While Tianjin and Beijing can only obtain a few positive external benefits from the Hebei $\mathrm{PM}_{2.5}$ control, other provinces adjacent to Hebei and outside the Jing-jin-ji region will share the most of positive external benefits. Hence, provinces should be prior to reduce their local haze to maximize their own benefits due to the restricted transmission factors as well as their special locations, which is a highlight difference to the amount goal of greenhouse gas reduction. The proposition illustrates that coalition should shift the best emission reduction site from the province with the least marginal control cost to the province with the most control effect within the region.

Since cooperation is superior to non-cooperation in most indicators, we will only discuss the cooperation situation in the following sections.

\subsubsection{Analysis of health benefits in cooperation}

Human health is an important driving force for $\mathrm{PM}_{2.5}$ control. In this section, we further analyze the sources of the health benefits.

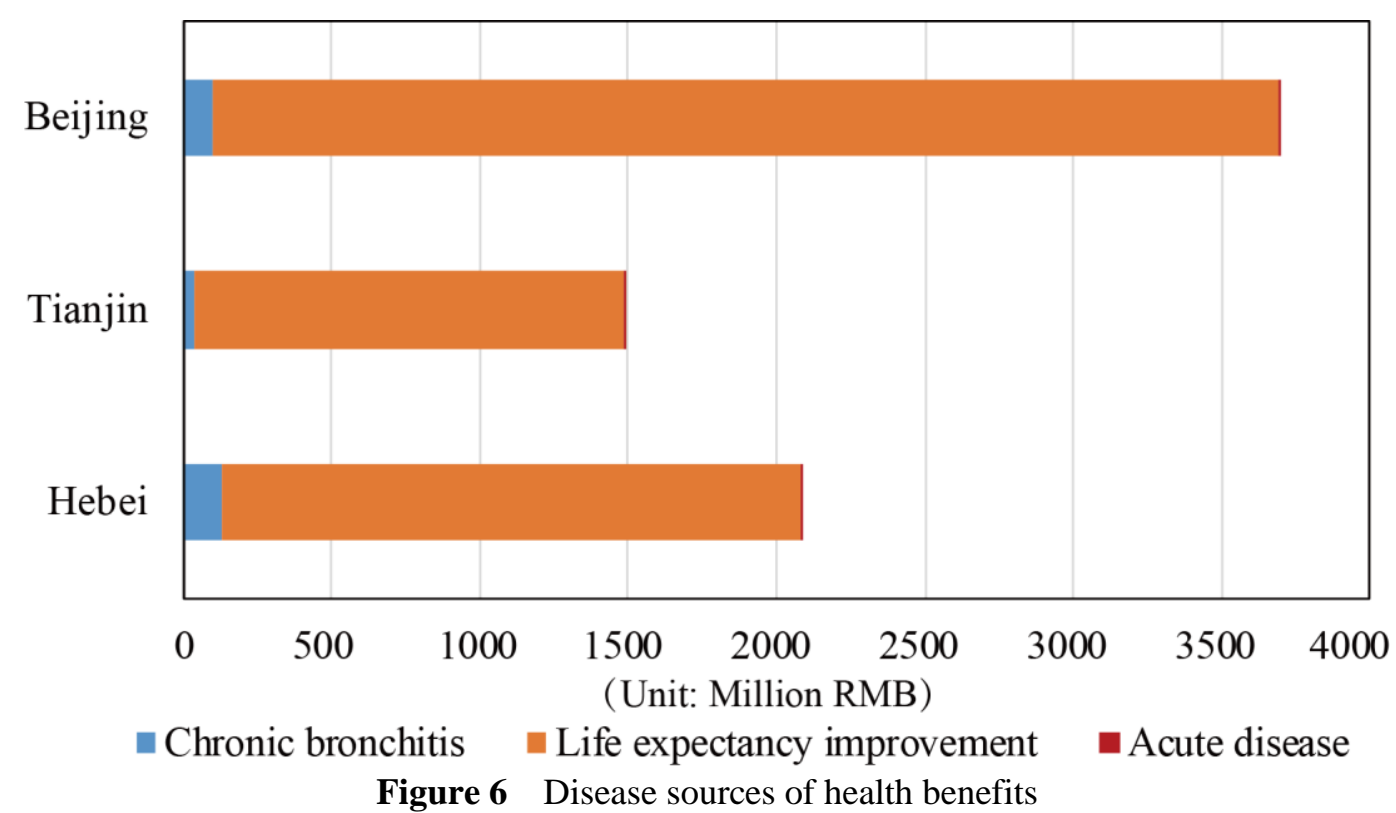

From Figure 6, we can see that in any region, the vast majority of the health benefits come from the increase in peoples' life expectancies, followed by decreased chronic 487 bronchitis. Acute diseases (including respiratory diseases, cardiovascular diseases, 
pediatrics, internal medicine, acute bronchitis, and asthma) have little or even negligible impacts on health benefits. For the treatment of $\mathrm{PM}_{2.5}$, the proportion of health benefits derived from the treatment costs is extremely low, and the vast majority come from the improvement of the environment, health improvement, and the reduction of time lost from work, which, in turn, increases the profit of the public and increases the output value of the companies. In other words, in terms of health benefits, the control of $\mathrm{PM}_{2.5}$ is a win-win option in the long run. The public has reduced their loss of work, the companies have increased their output value, and the government can then collect more taxes. Every stratum in the region will have an incentive to urge the government to control $\mathrm{PM}_{2.5}$.

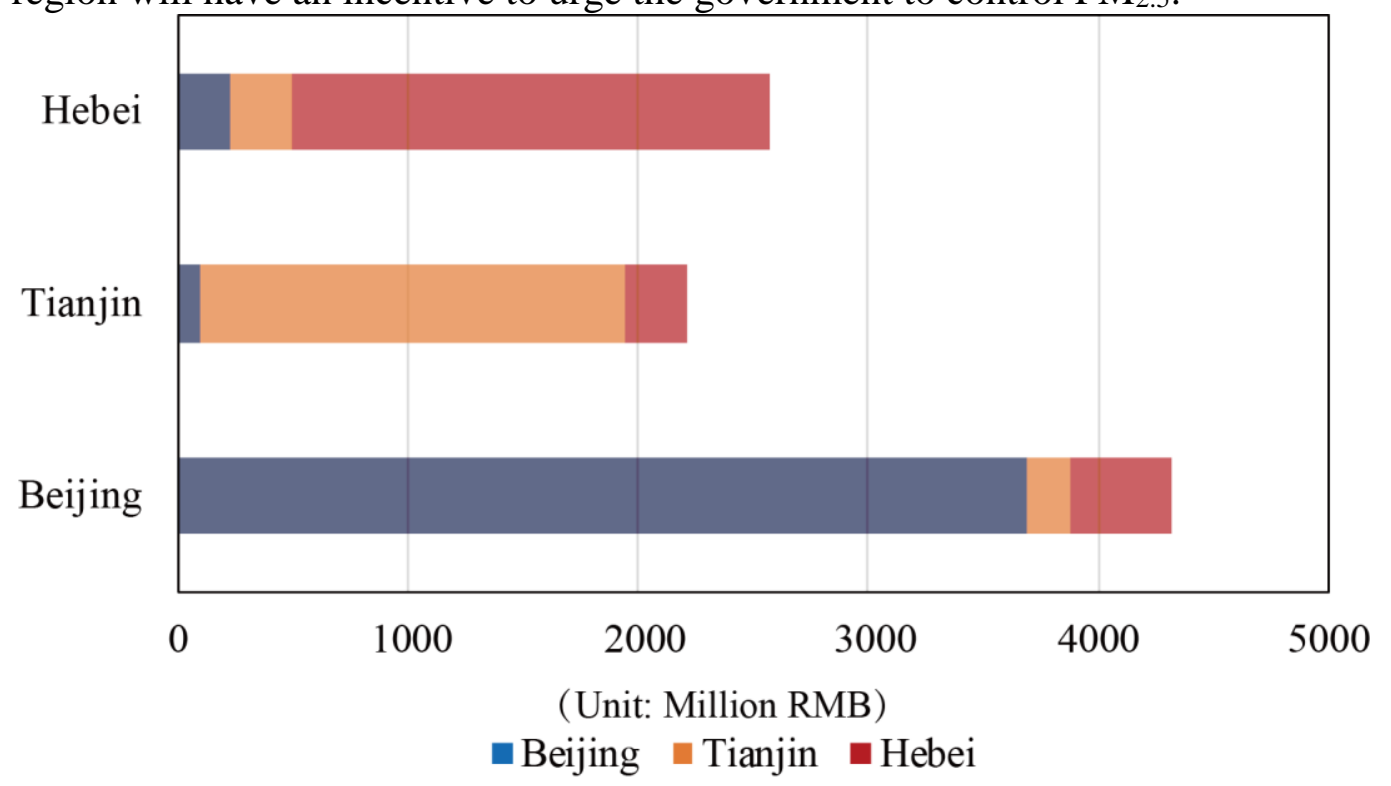

Figure 7 Province sources of health benefits

Figure 7 shows the health benefits from different provinces. As shown in Figure 3, $\mathrm{PM}_{2.5}$ control in Beijing reduces the local concentrations and those in Tianjin and Hebei by 16.52 $\mu \mathrm{g} / \mathrm{m}^{3}, 0.85 \mu \mathrm{g} / \mathrm{m}^{3}$, and $1.94 \mu \mathrm{g} / \mathrm{m}^{3}$, respectively. Corresponding to Figure 7, the $\mathrm{PM}_{2.5}$ control in Beijing increases the local health benefits and those in Tianjin and Hebei by 3.689 billion Yuan, 0.19 billion Yuan, and 0.442 billion Yuan, respectively, totaling 4.321 billion Yuan. According to Figure 7, we find that if a district controls the $\mathrm{PM}_{2.5}$, then the district receives most of the health benefits. If the local government wants to guarantee the health of the local people effectively, then it needs to concentrate on local control. The free rider only brings a few health benefits. In the cooperation situation, the health benefits brought by the $\mathrm{PM}_{2.5}$ control of Beijing, Tianjin, and Hebei are 4.321 billion Yuan, 1.848 billion Yuan, and 2.575 billion Yuan, respectively. The direct costs in Beijing, Tianjin, and Hebei are 1.535 billion Yuan, 7.608 billion Yuan, and 5.406 billion Yuan, respectively. Using the ratio (health benefits/direct costs), we only considered the cost-effectiveness of the direct costs in terms of health, and the result is Beijing > Hebei > Tianjin.

\subsubsection{Analysis of the economic development effect on cooperation}

we further analyze the economic development effects of various industries in the region. Figure 8 shows that the industrial structures of Beijing, Hebei and Tianjin are different. Beijing is a service-oriented city with tertiary industry, while Hebei and Tianjin are still in an industrial stage. Beijing's manufacturing/industrial output value is relatively small, accounting for only $12 \%$ of the aggregate GDP, while it is $42 \%$ and $46 \%$ in Tianjin and 
520 Hebei, respectively. At the same time, Beijing's tertiary industries, such as education, 521 culture and entertainment, scientific research, and finance, are particularly developed, 522 surpassing the sum of Hebei and Tianjin.

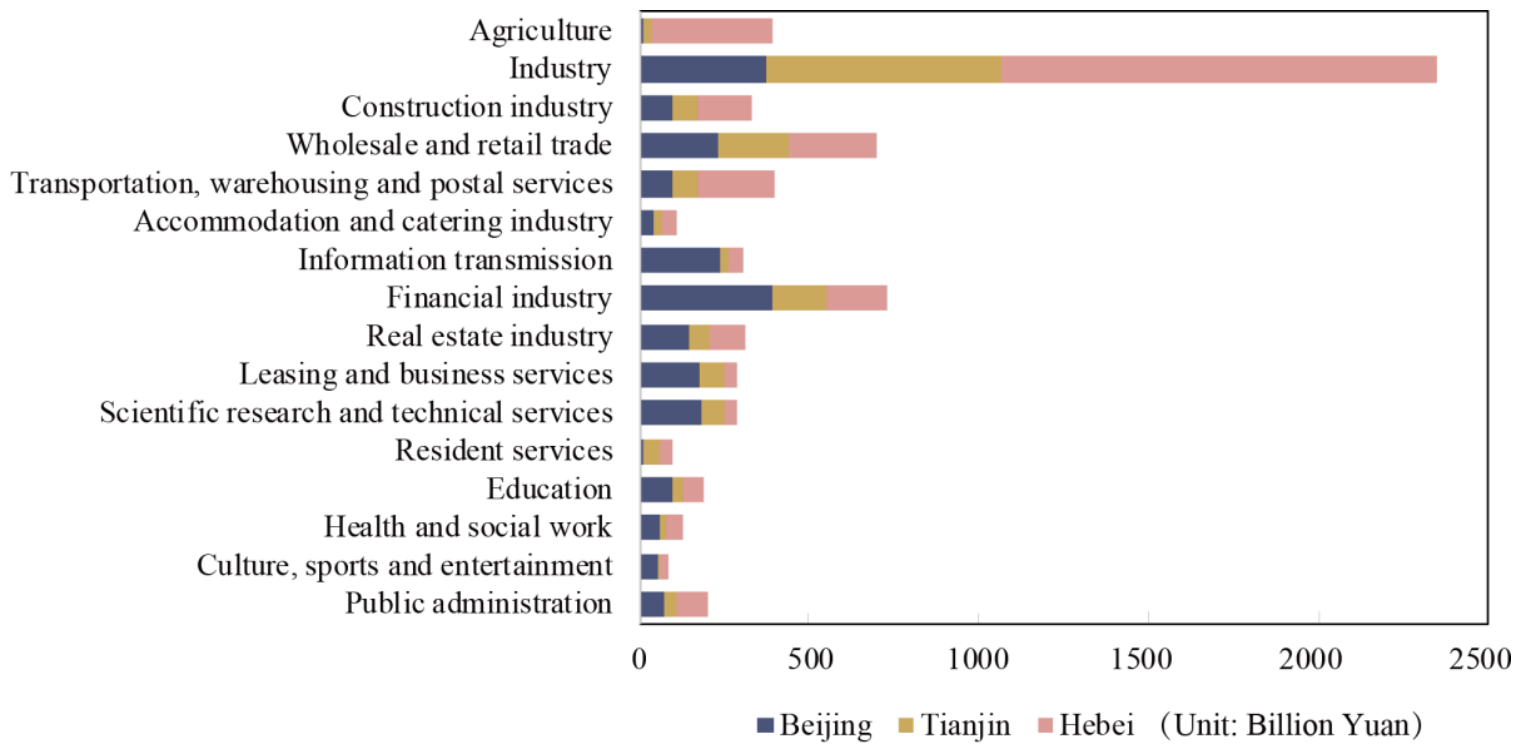

Figure 8 Industrial structures of Beijing, Tianjin and Hebei

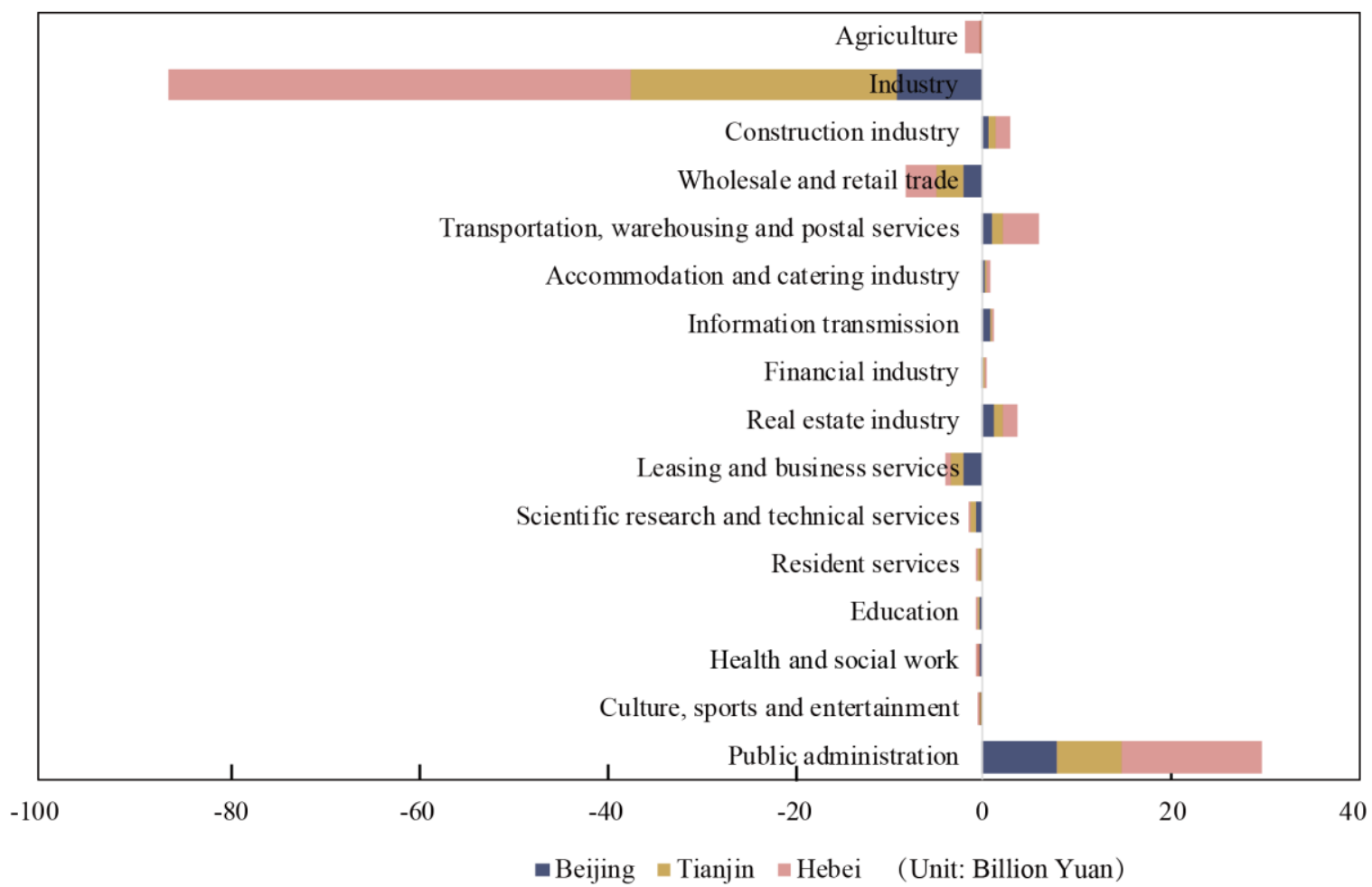

Figure 9 Industrial structure of Beijing, Tianjin and Hebei

Figure 9 shows the following: (1) The $\mathrm{PM}_{2.5}$ control plays a negative role on the economic development, which is 2.266 billion Yuan for Beijing, 23.492 billion Yuan for 
Tianjin, and 33.270 billion Yuan for Hebei. In general, the $\mathrm{PM}_{2.5}$ control has a catalytic effect on the development of tertiary industries and an inhibitory effect on the development of secondary industries. Combined with the direct costs, we only considered the costeffectiveness of direct costs in terms of economic development, and the result is Beijing > Hebei > Tianjin. However, considering the economic development and health benefits, the result is still Beijing > Hebei > Tianjin. The province benefitting most from the $\mathrm{PM}_{2.5}$ control in the Jing-jin-ji is Beijing, followed by Hebei, and finally Tianjin. (2) In the cooperation situation, whatever the service-oriented and industrial cities, the manufacturing/industry in the secondary industries have a majority of the negative economic development effects. Tianjin and Hebei are expected to bear 28.249 billion Yuan and 48.995 billion Yuan, respectively, accounting for $80 \%$ of all local negative economic development effects and $0.8 \%$ of GDP. The effects on Beijing are 9.015 billion Yuan, accounting for $63 \%$ of all local negative economic development effects and $0.4 \%$ of GDP. (3) Not all secondary industries will be affected in the $\mathrm{PM}_{2.5}$ control. The $\mathrm{PM}_{2.5}$ control is often accompanied by an upgrading of infrastructure, improving the local living environment and increasing peoples' willingness to live. As a result, the construction industry has developed, and the real estate industry that is closely associated with it has also developed. (4) $\mathrm{PM}_{2.5}$ control does not have a significant positive effect on most tertiary industries. For example, finance is the industry with the highest value in Beijing; the output value is as high as 39.26 billion Yuan, but $\mathrm{PM}_{2.5}$ control is expected to only bring 0.18 billion Yuan to the finance industry. $\mathrm{PM}_{2.5}$ control even causes a slight impediment to the development of certain tertiary industries. The benefits of $\mathrm{PM}_{2.5}$ control to public management and social security is clear. Some of the sub-sectors in this industry have extremely high requirements for air quality, such as pensions. $\mathrm{PM}_{2.5}$ control is expected to bring about a 7\% improvement in output value for public management and social security, accounting for over $70 \%$ of the positive economic development effects. In Beijing especially, it has brought a positive effect of 7.944 billion Yuan, offsetting the negative effects of $\mathrm{PM}_{2.5}$ control on manufacturing/industry. However, in public management and social security, Beijing does not have obvious advantages over the other two provinces. The positive effects of Tianjin and Hebei in the industry are 6.743 billion Yuan and 14.692 billion Yuan, respectively.

Figures 8 and 9 reflect the control dilemmas of different cities under different industrial structures. Beijing accounts for a large proportion of the tertiary industry. The industrial structure can offset the negative effects of $\mathrm{PM}_{2.5}$ control on industry/manufacturing. Naturally, there is sufficient incentive to control $\mathrm{PM}_{2.5}$. This is also true in practice. In the $\mathrm{PM}_{2.5}$ control in the Jing-jin-ji region, Beijing has always been an advocate and sponsor. In Tianjin and Hebei, the secondary industry plays an important role on the industrial structure. These provinces do not have sufficient motivation to control the $\mathrm{PM}_{2.5}$. However, if they do not control the $\mathrm{PM}_{2.5}$ actively, it will be difficult to achieve significant results in the control of the $\mathrm{PM}_{2.5}$ in the region due to cross-border pollution effects. In addition, we find that the $\mathrm{PM}_{2.5}$ control has an interaction and counteraction on economic development. When the local industrial structure does not match with the $\mathrm{PM}_{2.5}$ control, the industries that benefit from $\mathrm{PM}_{2.5}$ control urge the local governments to control the $\mathrm{PM}_{2.5}$. For example, in recent years, the upgrading of the industrial structure in the Jing-jin-ji region has brought many job opportunities and the rapid development of the real estate industry. Because the real estate industry is closely related to the local environmental quality, the 
real estate industry has provided positive incentives for local governments to control $\mathrm{PM}_{2.5}$. At the same time, the $\mathrm{PM}_{2.5}$ control has further promoted the development of the real estate industry. After the $\mathrm{PM}_{2.5}$ control, the industries benefiting from the improvement of the environment also develop rapidly. In 2015, the environment was greatly improved, and the output value of the Public Management and Social Security in Beijing's industry increased by $30 \%$.

Compare to the related literature about the health benefits of $\mathrm{PM}_{2.5}$ control such as $\mathrm{Yu}$ et al. (2015), our work expose the origin of health benefits by transmission matrix and know free rider is unrealistic fantasy. Compare to the previous literature about $\mathrm{SO}_{2}$ control (Zhao et al. (2013), Xue J et al. (2014, 2015), Wu et al. (2015), Shi et al. (2016) and Xie et al. (2016), we present a more reasonable concentration-based air pollution control game model and analyze the effect on economic development and get some insightful conclusion and our cost-effectiveness could explain the phenomenon the local governments overfull their targets.

\section{Conclusions and policy Implications}

According to the actual $\mathrm{PM}_{2.5}$ control situation, the big bubble hypothesis is not used and the direct removal costs, economic development effect and health benefits are considered in this study. The optimal removal model with $\mathrm{PM}_{2.5}$ 's transmission and retention factor is constructed. In addition, a strategy is provided under the condition that some provinces cannot achieve the emission reduction target and need a regional allocation based on the welfare function. Using the Jing-Jin-Ji region as an example, we conclude that the cooperative operation is more suitable than the non-cooperative operation, which can reflect several factors. Compared with the non-cooperative case, the cooperative case reduces the indirect cost by 1.59 Yuan RMB per $1 \mathrm{RMB}$. In the cooperation scenario, Beijing should transfer 0.373 billion Yuan RMB to Tianjin and Hebei should transfer 1.622 billion to Tianjin, while Tianjin will receive 19.95 billion RMB from Beijing and Hebei. The benefits increased by 2.318 billion Yuan.

In the Jing-Jin-Ji region, even in the cooperative model, $\mathrm{PM}_{2.5}$ control must involve a great deal of indirect cost. These three provinces also must accept an additional loss of 3.56 RMB for every 1 RMB direct $\mathrm{PM}_{2.5}$ removal cost. The distribution of the loss is also very unbalanced. Without a cost transfer, Beijing has no loss, while Hebei undertakes the largest removal task and experiences the greatest loss. Thus, the central government should develop a reasonable plan and compensation arrangement so that the $\mathrm{PM}_{2.5}$ control achieves the desired results. For air pollutants control under concentration control, the transfer matrix is a very important factor. Unlike the existing total amount control researches, the coalition should shift the best emission reduction site from the province with the least marginal control cost to the province with the most control effect within the region.

Moreover, the construction of the benefits transfer institution is less important than the transformation of the industrial structure. Under the existing conditions, we can develop specific industries that produce synergies with the $\mathrm{PM}_{2.5}$ control, especially public management and social security, which can provide additional incentives to control the $\mathrm{PM}_{2.5 .} \mathrm{PM}_{2.5}$ control has an interaction and counteraction on economic development. When the local industrial structure does not match with the $\mathrm{PM}_{2.5}$ control, industries that benefit from $\mathrm{PM}_{2.5}$ control will urge local governments to control the $\mathrm{PM}_{2.5}$. In terms of health 
benefits, if a district controls the $\mathrm{PM}_{2.5}$, the district will receive most of the health benefits. If the local government wants to guarantee the health of the local people effectively, it needs to concentrate on local control. The free rider system only bring a few health benefits. Based on this article, we propose the following policy recommendations: for the central government, providing accurate information about transmission matrix is vital to $\mathrm{PM}_{2.5}$ control which the local governments do not have enough ability to grasp it exactly. It is indemnification for the complete of targets and important promote to achieve cooperation. If the local governments know it, they will can find free rider is unrealistic fantasy and control $\mathrm{PM}_{2.5}$. There is a relation between the emission reduction targets of the various provinces in the region due to the transmission matrix. The setting of emission reduction targets has externalities in other provinces, and we will discuss the setting of emission in the next article. The $\mathrm{PM}_{2.5}$ control process needs to be accompanied by the upgrading and transformation of the industrial structure. As China's population gradually ages, the prospects for the pension industry are bright. There are many elderly people with rich pensions, especially in the Jing-jin-ji region. The pension industry demands very high local air quality. If the local pension industry is vigorously developed, the local government will have the incentive to control air pollutants spontaneously. The pension industry needs a large amount of manpower to take care of occupations, such as nursing care. This industry can also effectively absorb the employed population and ease the government's concerns about unemployment caused by environmental governance. Therefore, the central government can promote the development of the pension industry in the Jing-jin-ji region. In addition, for the moment, the health benefits from the $\mathrm{PM}_{2.5}$ control in the Jing-jin-ji region are still lower than the economic development effects and direct costs. From an economic point of view, $\mathrm{PM}_{2.5}$ control is not worthwhile. Thus, in the process of control, it is necessary to publicize the necessity of $\mathrm{PM}_{2.5}$ control, increase people's perception of the health benefits of $\mathrm{PM}_{2.5}$ control, make $\mathrm{PM}_{2.5}$ control a priority among the people, and urge the government to initiate control.

\section{Acknowledgements}

The research is supported by the National Natural Science Foundation of China (NSFC) under the Grant 71874112, 71532002, 71801016, and 71871002, the Beijing Education Commission Social Science Program general program, and the Capacity Building for SciTech Innovation-Fundamental Scientific Research Funds of Capital Normal University.

\section{Appendix}

\subsection{Transmission Matrix}

At present, there are few studies (Xue et al., 2014b) on the transfer matrix. In this paper, we used the transport matrix from the Environmental Planning Institute of the Ministry of Environmental Protection in 2010 and 2015. According to the matrix, we obtained Tables 1 and 2:

Table 1 Retention matrix (2010)

\begin{tabular}{cllll}
\hline Province & Beijing & Hebei & Tianjin & Others \\
\hline Beijing & $63 \%$ & $24 \%$ & $4 \%$ & $9 \%$
\end{tabular}




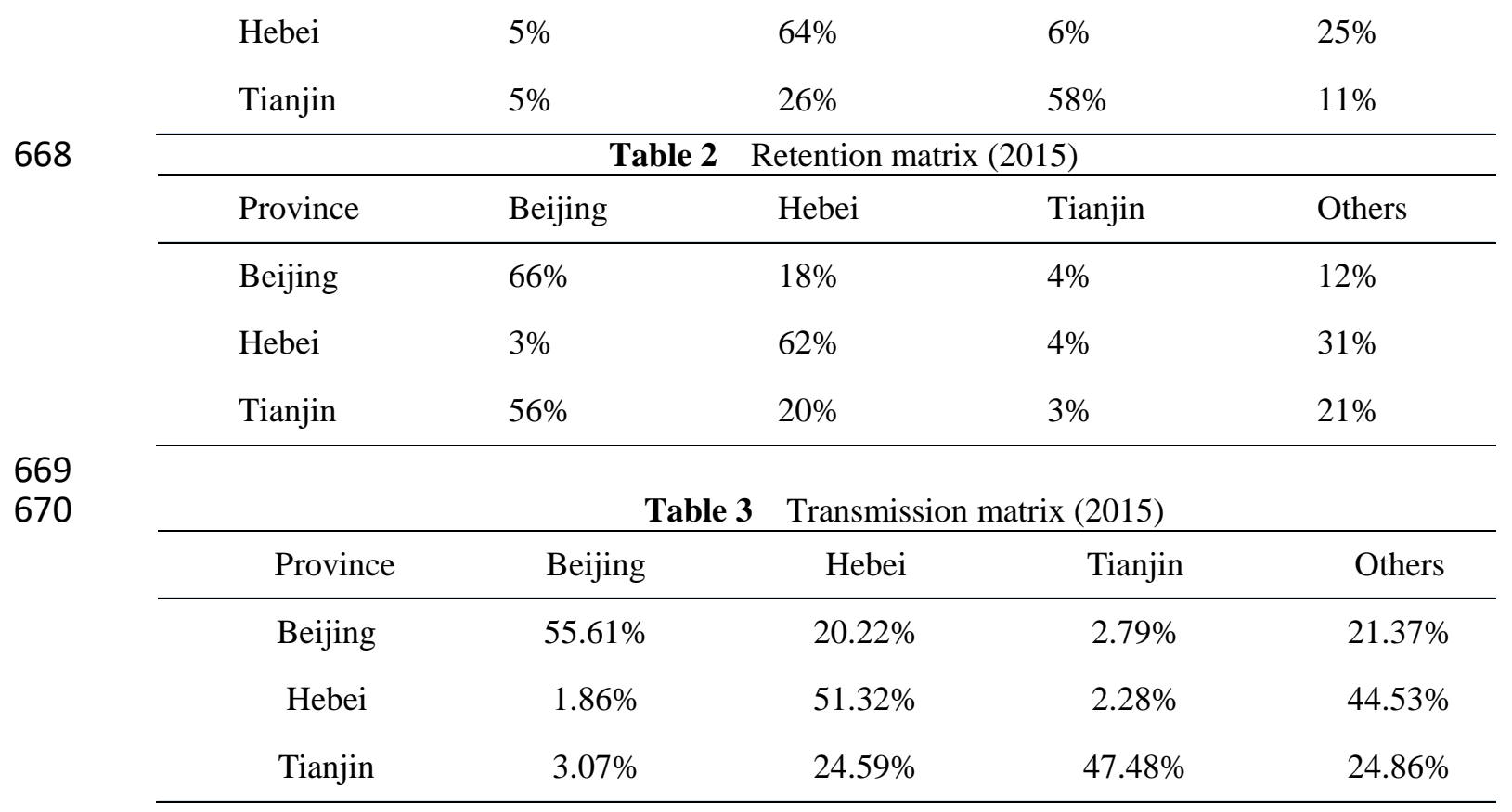

671

672

673

According to Table 1 and Table 2, we can see that in 2010 and 2015, although the 674 difference of the transmission matrix is not significant, so we assume in this paper that the 675 transport matrix remains the same in this year's $\mathrm{PM}_{2.5}$ control .

676 Table $2\left(\xi_{j i}\right)$ can be obtained directly from the Ministry of Environmental Protection's 677 matrix. Table $3\left(\delta_{j i}\right)$ needs to be combined with Table $2\left(\xi_{j i}\right), \beta_{i}$ and the concentration $678\left(c_{i}\right)$. Finally, the transmission matrix for province $j$ to another province $k$ is $679 \quad \delta_{j k}=\frac{\xi_{j k} \cdot \beta_{k} \cdot c_{k}}{\sum_{i=1}^{n} \xi_{j i} \cdot \beta_{i} \cdot c_{i}}$.

\subsection{Function-related Parameters}

\subsubsection{Direct costs function fitting result}

Table 4 Jing-jin-ji region's removal cost function of $\mathrm{SO}_{2}$ regression results

\begin{tabular}{ccl}
\hline & Variable & Coefficient \\
\hline Beijing & $R^{2}$ & 0.959 \\
& $F$ & 5.778 \\
& Sig. & 0.301 \\
\hline Tianjin & $R^{2}$ & 0.945 \\
& $F$ & 0.109 \\
& Sig. & 0.961 \\
\hline Hebei & $R^{2}$ & 0.775
\end{tabular}




\begin{tabular}{ccc}
$F$ & 0.863 \\
Sig. & 0.658 \\
\hline
\end{tabular}

686

687

688

689

690

691

692

693

694

695

696

697

698

699

700

701

702

\subsubsection{Health benefits function-related parameters}

According to the environmental bulletin, the average concentrations of $\mathrm{PM}_{2.5}$ in Beijing, Tianjin and Hebei in 2014 are $81 \mu \mathrm{g} / \mathrm{m}^{3}, 86 \mu \mathrm{g} / \mathrm{m}^{3}$ and $90 \mu \mathrm{g} / \mathrm{m}^{3}$, respectively. In this paper, the exposed population is the residential population at the end of 2014. The benchmark incidences of the health terminals were obtained from the relevant social-economic statistical yearbook or health statistics yearbook, and the coefficient of the reaction under the exposure was obtained from the relevant research of the previous scholars' methods (Huang and Zhang, 2013; Miao et al., 2017; Huang et al., 2012). The average age of chronic bronchitis is approximately 55 years old. The expected life expectancy is 82 , and the discount rate is $4.9 \%$. $\quad c$ and $\beta$ are 0.16 and 0.04 , respectively. According to Eq.(6), the Daly value is approximately 11.51 .

\subsubsection{Economic development effect function-related parameter}

Table 5 Impact of environmental regulation on output of 2015 industry

\begin{tabular}{|c|c|c|c|}
\hline Industry & $\begin{array}{c}\text { Output of } \\
2015 \text { Industry }(\%)\end{array}$ & Industry & $\begin{array}{l}\text { Output of } 2015 \\
\text { Industry }(\%)\end{array}$ \\
\hline Agriculture & -0.2 & $\begin{array}{l}\text { Electricity, heat } \\
\text { production and supply } \\
\text { industry }\end{array}$ & -0.78 \\
\hline $\begin{array}{l}\text { Coal mining and washing } \\
\text { industry }\end{array}$ & -4.39 & $\begin{array}{l}\text { Gas production and } \\
\text { supply }\end{array}$ & -1.07 \\
\hline Oil and gas extraction industry & 0.18 & $\begin{array}{l}\text { Water production } \\
\text { and supply }\end{array}$ & -0.36 \\
\hline Metal mining industry & -2.63 & $\begin{array}{l}\text { Construction } \\
\text { industry }\end{array}$ & 0.42 \\
\hline Non-metallic mining industry & -1.02 & $\begin{array}{l}\text { Transportation and } \\
\text { warehousing }\end{array}$ & -0.26 \\
\hline $\begin{array}{l}\text { Food manufacturing and } \\
\text { tobacco processing industry }\end{array}$ & -0.37 & Postal service & 0.94 \\
\hline Textile industry & -1.7 & $\begin{array}{c}\text { Information } \\
\text { transmission, computer } \\
\text { services and software } \\
\text { industry }\end{array}$ & 0.23 \\
\hline $\begin{array}{l}\text { Clothing, leather, down and its } \\
\text { products industry }\end{array}$ & -1.26 & $\begin{array}{l}\text { Wholesale and retail } \\
\text { trade }\end{array}$ & -0.54 \\
\hline $\begin{array}{l}\text { Wood processing and furniture } \\
\text { manufacturing }\end{array}$ & -0.36 & $\begin{array}{l}\text { Accommodation and } \\
\text { catering }\end{array}$ & 0.35 \\
\hline $\begin{array}{l}\text { Paper printing and cultural and } \\
\text { educational supplies manufacturing } \\
\text { industry }\end{array}$ & -1.23 & $\begin{array}{r}\text { Financial and } \\
\text { insurance industry }\end{array}$ & 0.03 \\
\hline $\begin{array}{l}\text { Oil processing, coking and } \\
\text { nuclear fuel processing industry }\end{array}$ & -1.88 & Real estate & 0.58 \\
\hline Chemical industry & -1.67 & $\begin{array}{r}\text { Leasing and } \\
\text { business services }\end{array}$ & -0.72 \\
\hline Non-metallic mineral products & -1.71 & Tourism & 0.64 \\
\hline
\end{tabular}


industry

Metal smelting and rolling

processing industry

Scientific research business

$-0.17$

Metal products industry

$-1.89$

Integrated technical

services

General purpose, special equipment manufacturing industry

$\begin{array}{lll}-0.84 & \text { Other social services } & -0.33\end{array}$

Transportation equipment

manufacturing industry

$-0.47$

Education

$-0.17$

Electrical, mechanical and equipment manufacturing

Communications equipment, computers and other electronic equipment manufacturing industry

Health, social security and social welfare

Instrumentation and cultural office machinery manufacturing industry

Culture, sports and entertainment

Other manufacturing + waste scrap

Public

$\begin{array}{lll}-7.18 & \text { administration and social }\end{array}$

organization

$-0.93$

\subsubsection{Model related parameter}

Table 6 Model related parameter

\begin{tabular}{|c|c|c|c|}
\hline & Beijing(B) & Tianjin(T) & Hebei $(\mathrm{H})$ \\
\hline \multicolumn{4}{|l|}{$\mathrm{Z}_{1}$ Direct cost } \\
\hline$\theta \cdot W_{i}^{\varphi}$ & 171888 & 1225290 & 2351410 \\
\hline$P_{i S O_{2 m i n}}$ & 4.07 & 4.95 & 41.36 \\
\hline$P_{i N O x \min }$ & 15.45 & 23.55 & 100.58 \\
\hline$P_{i P P M_{2.5} \min }$ & 4.53 & 3.80 & 32.42 \\
\hline$\mu_{\mathrm{SO}_{2}}$ & -0.060 & -0.775 & -0.209 \\
\hline$\mu_{N O_{x}}$ & -0.210 & -0.088 & -0.012 \\
\hline$\mu_{P P M_{2.5}}$ & -0.056 & -0.259 & -0.126 \\
\hline$t_{i}$ & 21.12 & 12.00 & 1.42 \\
\hline \multicolumn{4}{|c|}{$\mathrm{Z}_{2}$ Healthy Benefit (Unit :Yuan ) } \\
\hline $\begin{array}{l}\text { Respiratory } \\
\text { diseases }\end{array}$ & 14.58 & 13.03 & 12.05 \\
\hline $\begin{array}{l}\text { Cardiovascular } \\
\text { diseases }\end{array}$ & 4.67 & 4.18 & 3.86 \\
\hline Pediatrics & 3.00 & 2.70 & 1.85 \\
\hline Internal medicine & 6.42 & 5.77 & 3.95 \\
\hline Acute bronchitis & 7.79 & 6.85 & 6.30 \\
\hline asthma & 3.25 & 2.90 & 2.55 \\
\hline Chronic & 637.65 & 555.93 & 587.69 \\
\hline
\end{tabular}




\begin{tabular}{|c|c|c|c|}
\hline \multicolumn{4}{|l|}{ bronchitis } \\
\hline $\mathrm{HCL}$ & 488657.6 & 527337.3 & 198776.7 \\
\hline \multicolumn{4}{|c|}{$Z_{3}$ Economic Development Effects } \\
\hline$\tau \cdot E_{i}^{2015} P_{i R}^{2015}$ & 1535830 & 24878400 & 254206000 \\
\hline$P_{i \min }$ & 13.70 & 17.03 & 100.67 \\
\hline \multicolumn{4}{|l|}{ Constraint } \\
\hline$\beta_{i}$ & 0.2331 & 0.3803 & 2.1111 \\
\hline$g_{i}$ & 4.2 & 2 & 7.2 \\
\hline$\delta_{B i}$ & 0.5561 & 0.0307 & 0.0186 \\
\hline$\delta_{T i}$ & 0.0279 & 0.4748 & 0.0228 \\
\hline$\delta_{H i}$ & 0.2022 & 0.2459 & 0.5132 \\
\hline$\sum_{j=1}^{n} \delta_{j i} P_{j}^{\prime}$ & 21.73 & 40.23 & 247.84 \\
\hline$P_{i S O_{2} \mathrm{Min}}$ & 4.07 & 4.95 & 41.36 \\
\hline$P_{i S O_{2} \operatorname{Max}}$ & 14.51 & 22.45 & 141.88 \\
\hline$P_{i N O_{X} M \text { in }}$ & 15.45 & 23.55 & 100.58 \\
\hline$P_{i N O_{X} \operatorname{Max}}$ & 29.19 & 40.60 & 196.88 \\
\hline$P_{i P P M_{25} M \mathrm{in}}$ & 4.53 & 3.80 & 32.42 \\
\hline$P_{i P P M_{25} \operatorname{Max}}$ & 14.83 & 9.34 & 78.91 \\
\hline Model solve & \multicolumn{3}{|c|}{$\operatorname{Max} \mathrm{Z}=\frac{Z_{2}-Z_{3}}{Z_{1}}=-3.56$} \\
\hline
\end{tabular}

708

709

710

711 According to Eqs. (23)-(26), the eigenvalues of the three provinces are shown in the

712 following Tables 7:

\subsection{Allocation Based on Shapley Value}

\begin{tabular}{|c|c|c|c|c|c|}
\hline Province & $R$ & $\phi$ & $\{\mathrm{T}\}$ & $\{\mathrm{H}\}$ & $\{\mathrm{T} \mathrm{H}\}$ \\
\hline \multirow{6}{*}{ Beijing } & $\tilde{\mathrm{V}}(\mathrm{R})$ & 0 & -1.5125 & -2.1140 & -3.5625 \\
\hline & $\tilde{v}(R \cup\{B\})$ & 0.0979 & -1.1183 & -2.2776 & -3.5587 \\
\hline & $\tilde{v}(R \cup\{B\})-\tilde{v}(R)$ & 0.0979 & 0.3942 & -0.1636 & 0.0038 \\
\hline & $|R|$ & 0 & 1 & 1 & 2 \\
\hline & $\mathrm{W}|\mathrm{R}|$ & 0.33 & 0.17 & 0.17 & 0.33 \\
\hline & $\mathrm{W}|\mathrm{R}| *[\tilde{\mathrm{v}}(\mathrm{R} \cup\{\mathrm{B}\})-\tilde{\mathrm{v}}(\mathrm{R})]$ & 0.0326 & 0.0657 & -0.0272 & 0.0013 \\
\hline \multirow{6}{*}{ Tianjin } & $\tilde{\mathrm{v}}(\mathrm{R})$ & 0 & 0.0979 & -2.1140 & -2.2776 \\
\hline & $\tilde{v}(R \cup\{T\})$ & -1.5125 & -1.1183 & -3.5625 & -3.5587 \\
\hline & $\tilde{V}(R \cup\{T\})-\tilde{v}(R)$ & -1.5125 & -1.2162 & -1.4485 & -1.2811 \\
\hline & $|R|$ & 0 & 0 & 1 & 2 \\
\hline & $\mathrm{W}|\mathrm{R}|$ & 0.33 & 0.17 & 0.17 & 0.33 \\
\hline & $\mathrm{W}|\mathrm{R}| *[\tilde{\mathrm{v}}(\mathrm{R} \cup\{\mathrm{T}\})-\tilde{\mathrm{v}}(\mathrm{R})]$ & -0.5041 & -0.2027 & -0.2414 & -0.4270 \\
\hline
\end{tabular}




\begin{tabular}{cccccc}
\hline & $\tilde{v}(\mathrm{R})$ & 0 & 0.0979 & -1.5125 & -1.1183 \\
\multirow{4}{*}{ Hebei } & $\tilde{v}(\mathrm{R} \cup\{\mathrm{H}\})$ & -2.1140 & -2.2776 & -3.5625 & -3.5587 \\
& $\tilde{\mathrm{v}}(\mathrm{R} \cup\{\mathrm{H}\})-\tilde{\mathrm{v}}(\mathrm{R})$ & -2.1140 & -2.3755 & -2.0500 & -2.4404 \\
$|R|$ & 0 & 1 & 1 & 2 \\
& $\mathrm{~W}|\mathrm{R}|$ & 0.33 & 0.17 & 0.17 & 0.33 \\
& $\mathrm{~W}|\mathrm{R}| *[\tilde{\mathrm{v}}(\mathrm{R} \cup\{\mathrm{H}\})-\tilde{\mathrm{v}}(\mathrm{R})]$ & -0.7047 & -0.3959 & -0.3417 & -0.8134 \\
\hline
\end{tabular}

714

715

716

717

718

719

720

721

722

723

724

725

726

727

728

729

730

731

732

733

734

735

736

737

738

739

740

741

According to Table7, the proportion of welfare for Beijing through the allocation $\phi_{B}(V)$ is $0.0326+0.0657-0.0272+0.0013=0.0723$. In the indirect cost of 3.5587 Yuan, Beijing needs to get 0.0723 Yuan of benefits.

The proportion of welfare for Tianjin through the allocation $\phi_{T}(V)$ is $=-1.3753$. Tianjin needs to undertake 1.3753 Yuan of indirect cost.

$$
\phi_{H}(V)=-2.2557 \text {. Hebei needs to undertake 2.2557 Yuan of indirect cost. }
$$

Before allocation, the welfare of the three provinces in the aggregate welfare were 0.0979 , -1.5125 and -2.1441 . According to the aggregate control cost, Beijing should transfer 0.373 billion Yuan RMB to Tianjin and Hebei should transfer 1.622 billion to Tianjin, while Tianjin will receive 19.95 billion RMB from Beijing and Hebei. The benefits increased by 2.318 billion Yuan.

\section{Reference}

Aunan K, Pan X C. 2004. Exposure-response functions for health effects of ambient air pollution applicable for China - a metaanalysis[J]. Science of the Aggregate Environment. 329(1-3): 3-16.

Baiti N S O A, Naghavi N, Fah B C Y. 2017. The Impact of Environmental Regulations, Corruption and Economic Freedom on Economic Growth: Empirical Evidence from China[J]. International Journal of Economics Finance. 9(11): 92.

CHINA, M. O. E. E. (2018) Technical guidelines for environmental impact assessment-Atmospheric environment. HJ2.2-2018 ed.[DB/OL]http://kjs.mee.gov.cn/hjbhbz/bzwb/other/pjjsdz/201808/W020180814672740551977.pdf ,2018-7-31

Cao D, Song CY, Wang JN, et al. 2009 Establishment and empirical analysis of joint pollutant cost reduction function[J]. Environmental Science Research, (03): 371-376.

Da-hai, X. and W. Yu, et al. (2016). "The atmospheric environmental capacity coefficient cumulative frequency curve fitting and its application." China Environmental Science 36(10): 2913-2922.

Delucchi M A, Murphy J J, Mccubbin D R. 2002. The health and visibility cost of air pollution: a comparison of estimation methods[J]. Journal of Environmental Management. 64(2): 139-152.

Du N, Cao D, Huifen Y. 2007. Research on the Cost Function of Air Pollution Control in Industrial Enterprises[J]. Science Technology and Engineering. (06): 1116-1118.

FAN, J. L., KE, R. Y., YU, S. \& WEI, Y. M. (2016), "How does coal-electricity price linkage impact on the profit of enterprises in China? Evidence from a Stackelberg game model", Resources Conservation \& Recycling, Vol. 129S0921344916302609.

FAN, J., CAO, Z., ZHANG, X., WANG, J. \& ZHANG, M. (2019), "Comparative study on the influence of final use structure on carbon emissions in the Beijing-Tianjin-Hebei region", Science of The Total Environment, Vol. 668271-282.

Li G. 2014 The Impact of Strengthening Environmental Regulatory Policy on China's Economy- Evaluation Based on CGE Model[J]. Chinese economist: English. (4): 30-41.

Liu, F. and Q. Zhang, et al. (2015). "High-resolution inventory of technologies, activities, and emissions of coal-fired power plants in China from 1990 to 2010." Atmospheric Chemistry and Physics,15,23(2015-12-01) 15(13): 18787-18837.

Huang D S, Zhang S Q. 2013. Health benefit evaluation for $\mathrm{PM}_{2.5}$ pollution control in Beijing-Tianjin-Hebei region of China[J]. China Environmental Science. 33(1): 166-174.

Huang D, Xu J, Zhang S. 2012. Valuing the health risks of particulate air pollution in the Pearl River Delta, China[J]. Environmental Science \& Policy. 15(1): 38-47.

Jorgenson D W, Wilcoxen P J. 1990. Environmental Regulation and U.S. Economic Growth[J]. Rand Journal of Economics. 21(2): $314-$ 340.

Miao W, Huang X, Song Y. 2017. An economic assessment of the health effects and crop yield losses caused by air pollution in mainland China[J]. Journal of Environmental Sciences. 56(6): 102.

Nondo C. 2010. An empirical analysis of the interactions between environmental regulations and economic growth[J]. Dissertations Theses - Gradworks. 90(A5): 4141-4154.

Shapley L S. 1952. A value for n-person games[J]: 307-317.

Shi G M, Wang J N, Fu F, et al. 2016. A study on transboundary air pollution based on a game theory model: Cases of $\mathrm{SO}_{2}$ emission reductions in the cities of Changsha, Zhuzhou and Xiangtan in China[J]. Atmospheric Pollution Research. 8(2): 244-252.

Tang X, Chen X, Tian Y. 2017. Chemical composition and source apportionment of $\mathrm{PM}_{2.5}$ : A case study from one year continuous sampling in the Chang-Zhu-Tan urban agglomeration[J]. Atmospheric Pollution Research. 8(5): 885-899. 
Wu D, Xu Y, Zhang S. 2015. Will joint regional air pollution control be more cost-effective? An empirical study of China's Beijing-

767 Xianjin-Hebei region[J]. Journal of Environmental Management. 149: 27-36. effects and pollutant reduction costs[J]. Science of the Aggregate Environment. 573: 458-469.

770 Xue J, Xie W L, Chang-Min L I, et al. 2014. Inter-provincial cooperative game model of Beijing,Tianjin and Hebei province air pollution control[J]. Xitong Gongcheng Lilun Yu Shijian/system Engineering Theory \& Practice. 34(3): 810-816.

Xue J, Zhao L, Fan L, et al. 2015. An interprovincial cooperative game model for air pollution control in China.[J]. Journal of the Air \& Waste Management Association. 65(7): 818-827.

Xue W B, Fu F, Wang J N, et al. 2014a. Modeling study on atmospheric environmental capacity of major pollutants constrained by $\mathrm{PM}_{2.5}$ compliance of Chinese cities[J]. China Environmental Science. 34(10): 2490-2496.

Xue W B, Fu F, Wang J N, et al. 2014b. Numerical study on the characteristics of regional transport of $\mathrm{PM}_{2.5}$ in China[J]. Zhongguo Huanjing Kexue/china Environmental Science. 34(6): 1361-1368.

Yao Q, Han SQ, Cai ZY. 2013. Analysis of pollution characteristics of $\mathrm{PM}_{2.5}$ and its secondary components in winter 2011 in Tianjin[J]. Environmental Chemistry. (2): 313-318

Yu F. 2009. China Environmental Economy Accounting Guide[M]. China Environmental Science Press.

Yu L, Wenbo X, Yanxi Z, et al. 2015. Health Benefit Assessment of the National Action Plan for Air Pollution Prevention and Control[J]. Environmental Management in China. 7(5): 50-53.

Zhao C X, Wang Y J, Wang Y Q, et al. 2013. Interactions between fine particulate matter $\left(\mathrm{PM}_{2.5}\right)$ and vegetation: A review[J]. Chinese Journal of Ecology. 32(8): 2203-2210.

Zhao F, Ming X U, Ye Q I. 2010 The Environmental and Economic Benefits of Automotive Restrictions in Beijing[J]. Ecological Economy.

Zhao L, Xue J, Li C. 2013. A bi-level model for transferable pollutant prices to mitigate China's interprovincial air pollution control problem[J]. Atmospheric Pollution Research. 4(4): 446-453.

Zhou Z, Yaoyao X, Hongxia S, et al. 2017. Interval Game Analysis of Government Subsidy's Prevention and Control Strategy for

Beijing-Tianjin-Hebei Fog[J]. System Engineering Theory and Practice. (10): 2640-2648. 